\title{
Curcumin eliminates the inhibitory effect of advanced glycation end-products (AGEs) on gene expression of AGE receptor-1 in hepatic stellate cells in vitro
}

\author{
Jianguo Lin, Youcai Tang, Qiaohua Kang and Anping Chen
}

Diabetes is featured by hyperglycemia, which facilitates the formation of advanced glycation end-products (AGEs). AGEs are a causal factor in development of diabetic complications. AGE receptor-1 (AGE-R1) is responsible for detoxification and clearance of AGEs. Type 2 diabetes mellitus is commonly accompanied by non-alcoholic steatohepatitis, which could cause hepatic fibrosis. Little attention has been paid to effects of AGEs on hepatic fibrogenesis. Curcumin, a phytochemical from turmeric, has been reported to inhibit the activation of hepatic stellate cells (HSCs), the major effectors during hepatic fibrogenesis, and to protect against hepatic fibrogenesis in vitro and in vivo. The current study was designed to evaluate the effects of AGEs on inducing HSC activation, to assess the role of curcumin in diminishing the AGE effects, and to explore the underlying mechanisms. Our results showed that AGEs stimulated HSC activation by inducing cell proliferation and expression of genes relevant to HSC activation, which were abrogated by curcumin. Curcumin induced gene expression of AGE-R1 in passaged HSCs, which might facilitate the attenuation of the stimulatory effects of AGEs on the activation of HSCs. Further experiments revealed that curcumin inhibited the activity of extracellular signal-regulated kinase (ERK), and induced gene expression and the activity of peroxisome proliferator-activated receptor-gamma (PPAR $\gamma$ ), leading to the induction of the AGE-R1 gene expression. In summary, AGEs stimulated HSC activation. Curcumin eliminated the AGE effects at least partially by inducing the $A G E-R 1$ gene expression. The process was mediated by inhibiting ERK activity, inducing gene expression of PPAR $\gamma$ and stimulating its transactivity.

Laboratory Investigation (2012) 92, 827-841; doi:10.1038/labinvest.2012.53; published online 26 March 2012

KEYWORDS: diabetes; gene expression; hepatic fibrosis; hepatic stellate cell; hyperglycemia

Type 2 diabetes mellitus (T2DM) is featured by insulinindependently elevated levels of blood glucose, ie, hyperglycemia. Hyperglycemia is a high-risk factor for the development of non-alcoholic steatohepatitis (NASH), ${ }^{1}$ which is an understudied complication of T2DM. Approximately $15-40 \%$ of NASH patients develop hepatic fibrosis. ${ }^{2}$ Hyperglycemia facilitates the non-enzymatic formation of advanced glycation end-products (AGEs), which are a heterogeneous group of molecules formed by non-oxidative and oxidative reactions of sugars with proteins and/or lipids. ${ }^{3}$ AGEs accumulate in tissues and circulation during aging, as well as diabetic, chronic renal failure and liver fibrogenesis, ${ }^{4}$ leading to inflammation and pathogenesis. ${ }^{5}$ Effects of AGEs are mediated by their receptor system, which could be generally divided into two categories. Receptor for AGEs (RAGE) facilitates oxidative stress (OS), cell growth and inflammation. ${ }^{6}$ AGE receptors (AGE-Rs), eg, AGE-R1 (also called OST-48), are responsible for detoxification and clearance of AGEs. ${ }^{7}$ In contrast to a dramatic increase in expression of RAGE in diabetes with high levels of AGEs, ${ }^{8}$ the abundance of AGE-R1 is significantly reduced in diabetic organs, eg, kidney, ${ }^{9}$ suggesting a possible inverse relationship between AGEs-mediated cell injury and low expression of AGE-R1. In addition to its participation in AGE removal, AGE-R1 negatively regulates AGE pro-inflammatory signal processing. ${ }^{7}$

Hepatic stellate cells (HSCs) are the major effectors during hepatic fibrogenesis. ${ }^{10}$ During hepatic injury, quiescent HSCs undergo profound phenotypic changes, including enhanced cell proliferation, loss of lipid droplets, de novo expression of $\alpha$-smooth muscle actin ( $\alpha$-SMA) and excessive production of extracellular matrix, including type I collagen. ${ }^{10}$ This process is called HSC activation. Freshly isolated HSCs spontaneously 
become fully activated in culture, ${ }^{11}$ mimicking the process seen in vivo. The spontaneous activation of HSCs during cell culture provides a good model for elucidating the underlying mechanisms of HSC activation and studying the potential therapeutic intervention of the process. ${ }^{10,12}$ Few effective medicines are currently available for inhibiting HSC activation and combating hepatic fibrosis, including T2DM- and $\mathrm{NASH}$-associated hepatic fibrosis. ${ }^{13}$ It is, therefore, of high priority to identify innocuous anti-fibrotic agents. Curcumin, the yellow pigment in curry from turmeric, has received attention as a promising dietary supplement for the protection against fibrogenic insults. ${ }^{14}$ We recently demonstrated that curcumin inhibited HSC activation and protected the liver from $\mathrm{CCl}_{4}$-caused injury in vitro and in vivo. ${ }^{15-18}$

The liver is not only a site for cleaning AGEs, but also a target organ for AGEs. Elevated levels of serum AGEs were observed in patients with NASH. ${ }^{19}$ However, little attention has been paid to effects of AGEs on HSC activation, and on T2DM- and NASH-associated hepatic fibrogenesis. AGEs were reported to induce the proliferation of cultured HSCs. ${ }^{20}$ The accumulation of AGEs and the reduction of the AGE-R1 abundance may represent important mediators in hyperglycemia-induced HSC activation. However, the underlying mechanism remains largely undefined. The current study was designed to evaluate the effects of AGEs on inducing HSC activation, to assess the role of curcumin in inhibiting the effects of AGEs, and to explore the underlying mechanisms. Results in this report supported our initial hypothesis that AGEs might stimulate HSC activation, which could be eliminated by curcumin at least partially by inducing $A G E-R 1$ gene expression.

\section{MATERIALS AND METHODS}

\section{AGE Preparation and Chemicals}

AGEs-bovine serum albumin (BSA) were prepared following the protocol described by others. ${ }^{21}$ In brief, $50 \mathrm{mg} / \mathrm{ml}$ of BSA (USB, Cleveland, OH, USA) and $0.5 \mathrm{M}$ of glucose (SigmaAldrich, St Louis, MO, USA) were dissolved in $0.2 \mathrm{M}$ of sodium phosphate buffer ( $\mathrm{pH}$ 7.4). A BSA control and a glucose control were respectively prepared by dissolving BSA $(50 \mathrm{mg} / \mathrm{ml})$ alone, or glucose $(0.5 \mathrm{M})$ alone, in sodium phosphate buffer ( $\mathrm{pH}$ 7.4) (0.2 M). After sterilization with sterile Acrodisc syringe filters, the solutions were incubated in the dark at $37^{\circ} \mathrm{C}$ for 60 days. Unbound materials were removed by extensive dialysis against phosphate-buffered saline.

The concentration of AGEs was determined as described, by measuring AGEs-specific fluorescence with excitation at $360 \mathrm{~nm}$ and emissions at $440 \mathrm{~nm} .^{22,23}$ The fluorescence of the BSA control was used as a base line. The fluorescence of qualified AGEs-BSA used in our experiments must be at least 70-fold high than that of the BSA control. The quality and eligibility of AGEs were evaluated and confirmed as suggested. ${ }^{24}$ No contamination with insulin-like growth factor-1 and/or endotoxin was detected. Curcumin (purity $>94 \%$ ) and 15-deoxy- $\Delta^{12,14}$-prostaglandin $\mathrm{J}_{2}\left(\mathrm{PGJ}_{2}\right)$ were purchased from Sigma. PD68235 (PD), a specific peroxisome proliferator-activated receptor-gamma (PPAR $\gamma)$ antagonist, was kindly provided by Pfizer (Ann Arbor, MI, USA) ${ }^{25}$ Rosiglitazone (Rosi; BRL 49653), purchased from Cayman Chemical (Ann Arbor, MI, USA), was dissolved in dimethyl sulfoxide $(100 \mathrm{mM})$. The extracellular signal-regulated kinase (ERK) inhibitor PD98059 was purchased from CalBiochem (La Jolla, CA, USA). Primary antibodies were purchased from Santa Cruz Biotech (Santa Cruz, CA, USA), unless otherwise noted, and were previously described. ${ }^{26}$

\section{Isolation and Culture of HSCs}

Male Sprague-Dawley rats (200-250 g), purchased from the Harlan Laboratories (Indianapolis, IN, USA), were housed in a temperature-controlled animal facility $\left(23^{\circ} \mathrm{C}\right)$ with a 12:12 h light-dark cycle, and allowed free access to regular chew and water ad libitum. HSCs were isolated by the pronase-collagenase perfusion in situ before density gradient centrifugation, as we previously described. ${ }^{16}$ The animal protocol for use of rats was approved by Institutional Animal Care and Use Committee of Saint Louis University. Freshly isolated HSCs were cultured in Dulbecco's modified Eagle's medium (DMEM) supplemented with $20 \%$ of fetal bovine serum (FBS) for $48 \mathrm{~h}$. Cells were passaged in DMEM with $10 \%$ of FBS. Semi-confluent HSCs with four to nine passages were used in experiments. In some of experiments, cells were cultured in serum-depleted DMEM for $24 \mathrm{~h}$ before treatment, which rendered HSCs more sensitive to exogenous stimuli. ${ }^{26}$ Cells were subsequently treated and cultured in serum-depleted media, which excluded the interference from other factors in FBS.

\section{Determination of Cell Proliferation In Vitro}

Cell growth was colorimetrically determined by using the non-radioactive cell proliferation assay kit (ie, MTS assays; Promega, Madison, WI, USA), following the protocol provided by the manufacturer. ${ }^{16}$

\section{Western Blotting Analyses}

Preparation of whole-cell extracts, SDS-PAGE, transblotting and subsequent immunoreactions were conducted as we previously described. ${ }^{16} \beta$-actin or $\beta$-tubulin was used as an invariant control for equal loading. Densities of bands in western blotting analyses were normalized with the internal invariable control. Levels of target protein bands were densitometrically determined by using Quantity One 4.4.1 (Bio-Rad, Hercules, CA, USA). Variations in the density were expressed as fold changes compared with the control in the blot.

\section{RNA Extraction and Real-Time PCR}

Total RNA was treated with DNase I before the synthesis of the first strand of cDNA. Real-time PCR was performed as we previously described using SYBR Green Supermix. ${ }^{16}$ The 
mRNA levels were expressed as fold changes after normalization with glyceraldehyde-3-phosphate dehydrogenase, as described by Schmittgen et al. ${ }^{27}$ The following primers were used for determining the level of rat AGE-R1 mRNA by real-time PCR: (F) 5'-GCT CTG ATA TCG GTG ACC CT- $3^{\prime}$, (R) $5^{\prime}$-TCG TAG TTG TGG TGG TCG AT-3'. Other primers used in this study have been described in our prior reports. ${ }^{26}$

\section{Plasmids and Transient Transfection Assays}

The cDNA expression plasmids pa-ERK and pdn-ERK, respectively, containing a full-length cDNA fragment encoding the constitutively active form of ERK (a-ERK), or the dominant-negative form of ERK (dn-ERK), were previously described and used. ${ }^{28}$ The PPAR $\gamma$ activity luciferase reporter plasmid pPPRE-TK-Luc was also previously described. ${ }^{16}$ The luciferase reporter plasmid pAGE-R1-Luc was generated by subcloning a fragment $(-3838 /+67 \mathrm{bp})$ of the murine $A G E-$ R1 gene promoter into HindIII/MluI sites of pGL3-Basic vector. Semi-confluent HSCs in six-well cell culture plates were transiently transfected with a total of 3-4.5 $\mu$ g DNA per well, using the LipofectAMINE reagent (Invitrogen, Carlsbad, CA, USA), as we previously described. ${ }^{16}$ Each sample was in triplicate in every experiment. Transfection efficiency was normalized by co-transfection of the $\beta$-galactosidase reporter plasmid pSV- $\beta$-gal $(0.5 \mu \mathrm{g} /$ well; Promega). The $\beta$-galactosidase activities were measured by using a chemiluminescence assay kit (Tropix, Bedford, MA, USA). Luciferase activities were expressed as relative unit after normalization with $\beta$-galactosidase activities per $\mu \mathrm{g}$ of protein. Results were combined from at least three independent experiments.

\section{Statistical Analyses}

Percentages in differences were calculated in the formula: ( \# in target HSCs - \# in compared HSCs)/\# in compared HSCs $) \times 100 \% \quad(n \geq 3)$. Differences between means were evaluated using an unpaired two-sided Student's test $(P<0.05$ considered as significant). Where appropriate, comparisons of multiple treatment conditions with control were analyzed by analysis of variance, with the Dunnett's test for post hoc analysis.

\section{RESULTS}

AGEs Stimulated HSC Proliferation and Induced Expression of Genes Closely Relevant to HSC Activation To determine effects of AGEs on inducing HSC activation, passaged HSCs were cultured in serum-depleted DMEM for $24 \mathrm{~h}$, which restored some of the quiescent phenotypes and made HSCs more sensitive to exogenous stimuli. ${ }^{26}$ Serumstarved HSCs were stimulated with AGEs-BSA, or BSA, at $0-200 \mu \mathrm{g} / \mathrm{ml}$ in serum-depleted media for $24 \mathrm{~h}$. Subsequent culture in serum-depleted DMEM eliminated the interference from growth factors in FBS. As shown in Figure 1a by cell proliferation assays, AGEs-BSA dose-dependently increased the number of viable cells. For instance, compared with the untreated control (the first black column), AGEs-BSA at $100 \mu \mathrm{g} / \mathrm{ml}$ significantly increased the number of viable HSCs by $95 \%$. However, BSA by itself had no such stimulatory effect on the number of viable HSCs (white columns). These results suggested that AGEs stimulated cell proliferation of HSCs in vitro.

Further experiments by real-time PCR (Figure 1b) and western blotting analyses (Figure 1c) indicated that AGEsBSA stimulated the gene expression of $\alpha \mathrm{I}(\mathrm{I})$ collagen and $\alpha$-SMA, two unique markers for activated HSCs. In addition, AGEs-BSA induced expression of genes relevant to cell growth, including pro-mitogenic PDGF- $\beta \mathrm{R}$, cyclin D1 and antiapoptotic Bcl-2, whereas it suppressed gene expression of pro-apoptotic Bax. Furthermore, AGEs-BSA induced expression of genes relevant to pro-fibrogenesis, including the type I and II TGF- $\beta$ receptors (T $\beta$-RI/II) and connective tissue growth factor (CTGF). In contrast, BSA by itself had no such dose-dependent effects on the regulation of expression of the genes (data not shown). These results collectively suggested that AGEs induced the activation of HSCs in vitro. As AGEs-BSA at $100 \mu \mathrm{g} / \mathrm{ml}$ was enough for inducing HSC activation, this concentration was chosen for the following experiments.

\section{Curcumin Eliminated the Effects of AGEs on the Induction of HSC Activation In Vitro}

Curcumin by itself has shown its effects on the regulation of expression of genes relevant to the activation of HSCs in vitro and in vivo, including $\alpha \mathrm{I}(\mathrm{I})$ collagen, ${ }^{15,16} \alpha$-SMA, ${ }^{15,16}$ TGF$\beta \mathrm{I} / \mathrm{II},{ }^{17} \mathrm{CTGF}^{29,30}$ Bax and BcL-2, ${ }^{17}$ and so on. To assess the role of curcumin in attenuating the stimulatory effects of AGEs on the activation of HSCs, serum-starved HSCs were treated with or without (w/wt) AGEs-BSA $(100 \mu \mathrm{g} / \mathrm{ml})$ in the presence of curcumin at indicated concentrations $(0-30 \mu \mathrm{M})$ in serum-depleted media for $24 \mathrm{~h}$. As shown in Figure 2a by cell proliferation assays, AGEs increased, as expected, the number of viable cells by $92 \%$ (the second column), compared with the untreated control (the first column). Curcumin dose-dependently eliminated the effect of AGEs. For instance, compared with AGEs alone (the second column), curcumin at $20 \mu \mathrm{M}$ diminished the effect of AGEs and reduced the number of viable cells by $33 \%$ (the fourth column).

Further experiments of real-time PCR (Figure 2b) and western blotting analyses (Figure 2c) revealed that curcumin eliminated the effect of AGEs on regulating expression of genes relevant to the activation of HSCs by reducing gene expression of $\alpha \mathrm{I}(\mathrm{I})$ collagen, $\alpha$-SMA, PDGF- $\beta \mathrm{R}$, cyclin D1, $\mathrm{Bcl}-2, \mathrm{~T} \beta$-RI/II and CTGF, as well as by inducing gene expression of Bax, at both levels of mRNA and protein. Taken together, these results demonstrated that curcumin eliminated the effects of AGEs on the induction of HSC activation in vitro. 


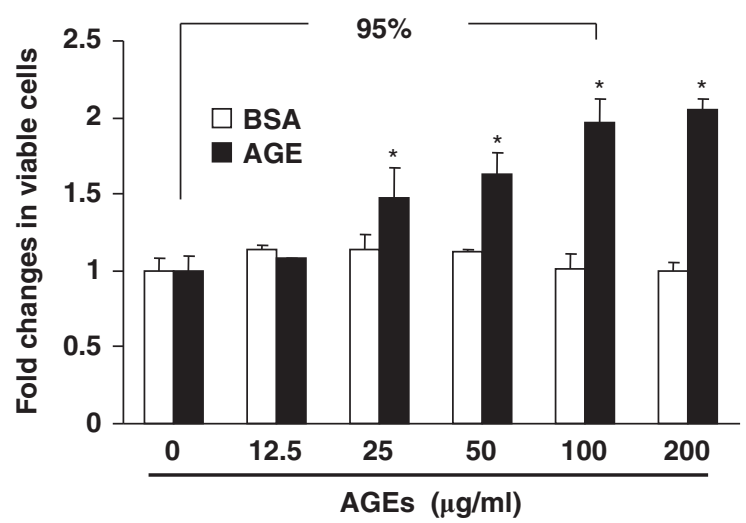

b

\begin{tabular}{|c|c|c|c|c|c|c|}
\hline AGE $(\mu \mathrm{g} / \mathrm{ml})$ & 0 & 12.5 & 25 & 50 & 100 & 200 \\
\hline$\alpha \mathrm{l}(\mathrm{I}) \mathrm{col}$ & 1 & $1.1 \pm 0.1$ & $1.4 \pm 0.3^{*}$ & $1.5 \pm 0.1^{*}$ & $1.7 \pm 0.1^{*}$ & $1.8 \pm 0.2^{*}$ \\
\hline$\alpha$-SMA & 1 & $1.0 \pm 0.0$ & $1.1 \pm 0.1^{*}$ & $1.2 \pm 0.1^{*}$ & $1.3 \pm 0.2^{*}$ & $1.4 \pm 0.2^{*}$ \\
\hline PDGF- $\beta R$ & 1 & $1.1 \pm 0.1$ & $1.2 \pm 0.2^{*}$ & $1.3 \pm 0.1^{*}$ & $1.4 \pm 0.1^{*}$ & $1.6 \pm 0.2^{*}$ \\
\hline Cyclin D1 & 1 & $1.0 \pm 0.0$ & $1.0 \pm 0.1$ & $1.1 \pm 0.1^{*}$ & $1.2 \pm 0.0^{*}$ & $1.3 \pm 0.0^{*}$ \\
\hline Bcl-2 & 1 & $1.0 \pm 0.1$ & $1.1 \pm 0.0^{*}$ & $1.2 \pm 0.0^{*}$ & $1.3 \pm 0.2^{*}$ & $1.5 \pm 0.2^{*}$ \\
\hline Bax & 1 & $0.9 \pm 0.0$ & $0.7 \pm 0.1^{*}$ & $0.6 \pm 0.1^{*}$ & $0.5 \pm 0.0^{*}$ & $0.4 \pm 0.1^{*}$ \\
\hline T $\beta-R I I$ & 1 & $1.1 \pm 0.1$ & $1.1 \pm 0.1$ & $1.3 \pm 0.1^{*}$ & $1.4 \pm 0.2^{*}$ & $1.4 \pm 0.2^{*}$ \\
\hline Tß-RI & 1 & $1.1 \pm 0.1$ & $1.2 \pm 0.1^{*}$ & $1.4 \pm 0.0^{*}$ & $1.5 \pm 0.0^{*}$ & $1.5 \pm 0.1^{*}$ \\
\hline CTGF & 1 & $1.0 \pm 0.0$ & $1.1 \pm 0.1$ & $1.2 \pm 0.2^{*}$ & $1.3 \pm 0.2^{*}$ & $1.3 \pm 0.1^{*}$ \\
\hline
\end{tabular}

C

\begin{tabular}{|c|c|c|c|c|c|c|c|}
\hline \multirow{3}{*}{ Fold } & 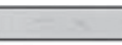 & & $\longrightarrow$ & $\longrightarrow$ & $=$ & $\longrightarrow$ & \multirow{4}{*}{$\alpha-S M A$} \\
\hline & 1 & $1.1 \pm 0.3$ & $1.3 \pm 0.3$ & $1.6 \pm 0.4$ & $1.9 \pm 0.4$ & $2.2 \pm 0.4$ & \\
\hline & & - & 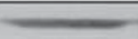 & 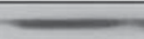 & 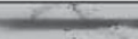 & - & \\
\hline \multirow[t]{2}{*}{ Fold } & 1 & $1.1 \pm 0.1$ & $1.4 \pm 0.3$ & $1.7 \pm 0.4$ & $2.2 \pm 0.4$ & $2.3 \pm 0.4$ & \\
\hline & & & $=$ & Z & - & - & \multirow[t]{2}{*}{ PDGF- $\beta R$} \\
\hline \multirow[t]{2}{*}{ Fold } & 1 & $1.1 \pm 0.1$ & $1.1 \pm 0.2$ & $1.3 \pm 0.1$ & $1.5 \pm 0.3$ & $1.7 \pm 0.3$ & \\
\hline & & & 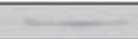 & 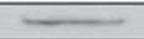 & 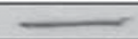 & 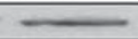 & \multirow[t]{2}{*}{ Cyclin D1 } \\
\hline \multirow[t]{2}{*}{ old } & 1 & $1.0 \pm 0.2$ & $1.1 \pm 0.2$ & $1.3 \pm 0.2$ & $1.5 \pm 0.3$ & $1.6 \pm 0.4$ & \\
\hline & & & $=$ & $=$ & $=$ & & \multirow[t]{2}{*}{ Bcl-2 } \\
\hline \multirow[t]{2}{*}{ Fold } & 1 & $1.1 \pm 0.2$ & $1.2 \pm 0.3$ & $1.4 \pm 0.4$ & $1.5 \pm 0.3$ & $1.7 \pm 0.3$ & \\
\hline & $=$ & 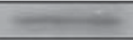 & $x^{2+2}$ & - & $\square$ & +2 & \multirow[t]{2}{*}{ Bax } \\
\hline \multirow[t]{2}{*}{ Fold } & 1 & $1.0 \pm 0.2$ & $0.9 \pm 0.1$ & $0.7 \pm 0.2$ & $0.5 \pm 0.2$ & $0.4 \pm 0.3$ & \\
\hline & - & 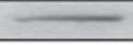 & $\bar{\square}$ & $\longrightarrow$ & $=$ & $=$ & \multirow[t]{2}{*}{ Th-RII } \\
\hline \multirow[t]{2}{*}{ Fold } & 1 & $1.2 \pm 0.3$ & $1.3 \pm 0.2$ & $1.7 \pm 0.4$ & $1.9 \pm 0.3$ & $2.1 \pm 0.4$ & \\
\hline & $=$ & - & 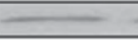 & 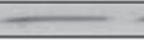 & - & & \multirow[t]{2}{*}{ T $\beta-R \mathbf{I}$} \\
\hline \multirow[t]{2}{*}{ Fold } & 1 & $1.1 \pm 0.2$ & $1.2 \pm 0.3$ & $1.3 \pm 0.2$ & $1.5 \pm 0.1$ & $1.5 \pm 0.2$ & \\
\hline & - & $=$ & -1. & 3 & 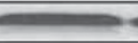 & 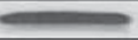 & \multirow[t]{2}{*}{ CTGF } \\
\hline \multirow[t]{2}{*}{ Fold } & 1 & $1.1 \pm 0.3$ & $1.5 \pm 0.3$ & $1.8 \pm 0.4$ & $2.2 \pm 0.4$ & $2.3 \pm 0.4$ & \\
\hline & & & E & - & $=$ & & \multirow[t]{2}{*}{$\beta$-actin } \\
\hline & 0 & 12.5 & 25 & 50 & 100 & 200 & \\
\hline
\end{tabular}

Figure 1 Advanced glycation end-products (AGEs) dose-dependently stimulated hepatic stellate cell (HSC) activation in vitro. HSCs were serum-starved in Dulbecco's modified Eagle's medium (DMEM) for $24 \mathrm{~h}$ before the stimulation with AGEs-bovine serum albumin (BSA), or BSA, at indicated doses in serumdepleted media for additional $24 \mathrm{~h}$. (a) Cell proliferation was determined by colorimetric MTS assays. Results were expressed as fold changes in the number of viable cells, compared with the untreated control (mean \pm s.d., $n=3$; the corresponding first column). The percentage in difference was calculated in the formula: ((\# in target HSCs - \# in compared HSCs)/\# in compared HSCs) $\times 100 \%$. ${ }^{\star} P<0.05$ vs the untreated control (the first column). (b) Real-time PCR analyses. Values were presented as mRNA fold changes (mean \pm s.d., $n=3$ ). ${ }^{*}<0.05$ vs the untreated control (the corresponding first column). (c) Western blotting analyses. Representatives were from three independent experiments. Then, $\beta$-actin was used as an internal control for equal loading. Italic numbers beneath blots were fold changes (means \pm s.d., $n=3$ ) in the densities of the bands compared with the control without treatment in the blot, after normalization with the internal invariable control. 


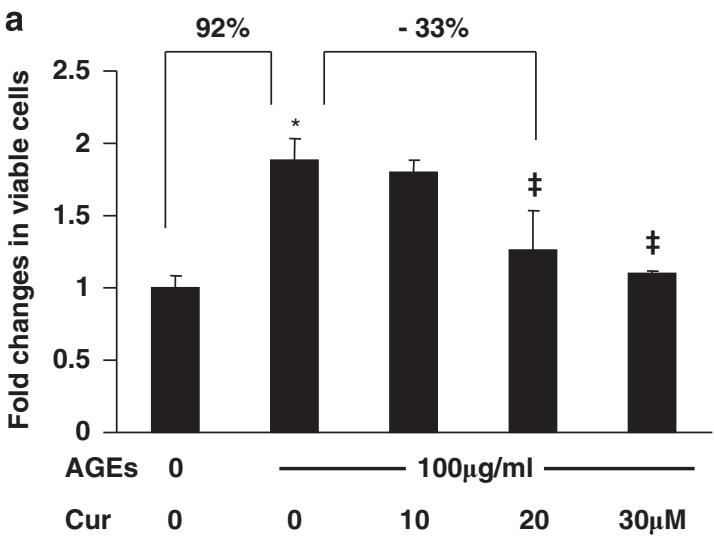

b

\begin{tabular}{|c|c|c|c|c|c|}
\hline AGE $(\mu \mathrm{g} / \mathrm{ml})$ & 0 & 100 & 100 & 100 & 100 \\
\hline Cur & 0 & 0 & 10 & 20 & 30 \\
\hline$\alpha \mathrm{l}(\mathrm{I}) \mathrm{col}$ & 1 & $1.7 \pm 0.3^{*}$ & $1.3 \pm 0.4^{\ddagger}$ & $0.9 \pm 0.2^{\ddagger}$ & $0.7 \pm 0.2^{\ddagger}$ \\
\hline$\alpha$-SMA & 1 & $1.4 \pm 0.1^{*}$ & $1.2 \pm 0.2$ & $0.9 \pm 0.2^{\ddagger}$ & $0.6 \pm 0.2^{\ddagger}$ \\
\hline PDGF- $\beta R$ & 1 & $1.7 \pm 0.3^{*}$ & $1.4 \pm 0.1^{\ddagger}$ & $0.9 \pm 0.2^{\ddagger}$ & $0.6 \pm 0.3^{\ddagger}$ \\
\hline Cyclin D1 & 1 & $1.5 \pm 0.2^{*}$ & $1.2 \pm 0.1^{\ddagger}$ & $0.8 \pm 0.2^{\ddagger}$ & $0.6 \pm 0.0^{\ddagger}$ \\
\hline $\mathrm{Bcl}-2$ & 1 & $1.6 \pm 0.2^{*}$ & $1.3 \pm 0.3^{\ddagger}$ & $0.8 \pm 0.2^{\ddagger}$ & $0.6 \pm 0.2^{\ddagger}$ \\
\hline Bax & 1 & $0.5 \pm 0.2^{*}$ & $0.7 \pm 0.2^{\ddagger}$ & $1.0 \pm 0.1^{\ddagger}$ & $1.3 \pm 0.0^{\ddagger}$ \\
\hline T $\beta$-RII & 1 & $1.4 \pm 0.3^{*}$ & $1.2 \pm 0.1$ & $0.9 \pm 0.1^{\ddagger}$ & $0.8 \pm 0.1^{\ddagger}$ \\
\hline Th-RI & 1 & $1.4 \pm 0.1^{*}$ & $1.2 \pm 0.2^{\ddagger}$ & $0.9 \pm 0.3^{\ddagger}$ & $0.8 \pm 0.1^{\ddagger}$ \\
\hline CTGF & 1 & $1.3 \pm 0.0^{*}$ & $1.2 \pm 0.2$ & $0.9 \pm 0.1^{\ddagger}$ & $0.7 \pm 0.1^{\ddagger}$ \\
\hline
\end{tabular}

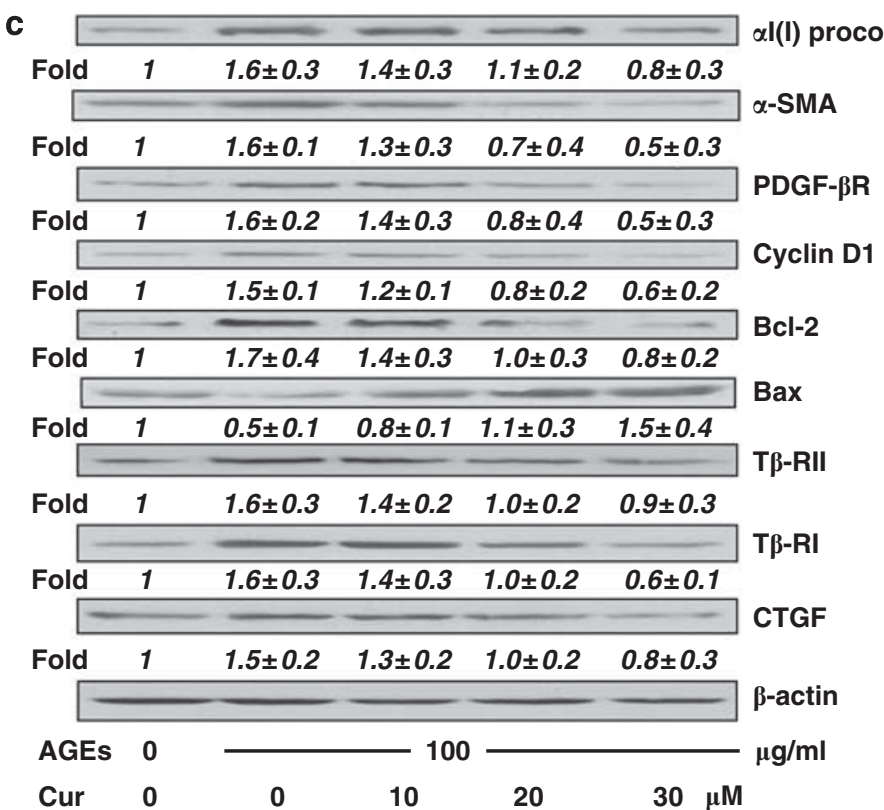

Figure 2 Curcumin eliminated the effects of advanced glycation end-products (AGEs) on the induction of HSC activation. Serum-starved hepatic stellate cells (HSCs) were treated with or without (w/wt) AGEs_bovine serum albumin (BSA) at $100 \mu \mathrm{g} / \mathrm{ml}$ plus or minus curcumin at indicated concentrations in serum-depleted media for $24 \mathrm{~h}$. (a) Cell proliferation was determined by MTS assays. Results were expressed as fold changes in the number of viable cells, compared with the untreated control (mean \pm s.d., $n=3$ ). ${ }^{*} P<0.05$ vs the untreated control (the first column); ${ }^{\ddagger} P<0.05$ vs cells treated with AGEs alone (the second column). The percentage in difference was calculated in the formula: ((\# in target HSCs - \# in compared HSCs)/\# in compared HSCs) $\times 100 \%$. (b) Real-time PCR analyses. Values were presented as mRNA fold changes (mean \pm s.d., $n=3$ ). ${ }^{\star} P<0.05$ vs the untreated control; ${ }^{\ddagger} P<0.05$ vs cells treated with AGEs alone. (c) Western blotting analyses. Representatives were from three independent experiments. Then, $\beta$-actin was used as an internal control for equal loading. Italic numbers beneath blots were fold changes (means \pm s.d., $n=3$ ) in the densities of the bands compared with the control without treatment in the blot, after normalization with the internal invariable control. 


\section{Curcumin Abrogated the Inhibitory Effect of AGEs and Induced Gene Expression of AGE-R1 in Passaged HSCs}

To elucidate the underlying mechanism by which curcumin eliminated the effects of AGEs on the induction of HSC activation, we assumed that one of the mechanisms for AGEs to induce HSC activation was to suppress the gene expression of AGE-R1, which could be attenuated by curcumin by inducing gene expression of AGE-R1. To test the assumption, serumstarved HSCs were stimulated with AGEs at indicated doses in serum-depleted media for $24 \mathrm{~h} \mathrm{w} / \mathrm{wt}$ the presence of curcumin $(0-30 \mu \mathrm{M})$. As shown in Figure $3 \mathrm{a}$ and b, respectively, by real-time PCR and western blotting analyses, AGEs dosedependently suppressed the gene expression of AGE-R1. For instance, compared with the untreated control (the first column and lane), AGEs at $100 \mu \mathrm{g} / \mathrm{ml}$ significantly reduced AGE-R1 at both levels of transcript and protein by approximately $70 \%$ (the fifth column and lane).

To evaluate the role of curcumin in regulating expression of AGE-R1, passaged HSCs were treated with curcumin at various concentrations in DMEM with $10 \%$ FBS for $24 \mathrm{~h}$. Western blotting analyses indicated that curcumin by itself increased the abundance of AGE-R1 in HSCs in a dosedependent manner (Figure 3c). Additional experiments revealed that curcumin dose-dependently attenuated the effect of AGEs by increasing gene expression of AGE-R1 demonstrated by real-time PCR (Figure 3d) and western blotting analyses (Figure 3e). For example, compared with AGEs alone (the second column and lane), curcumin at $20 \mu \mathrm{M}$ diminished the effect of AGEs and increased the levels of mRNA and protein by more than $150 \%$ (the fourth column and lane). Prior studies have shown that serum starvation partially restored phenotypic features of quiescent HSCs, including reduced levels of $\alpha \mathrm{I}(\mathrm{I})$ collagen and $\alpha$-SMA. ${ }^{26}$ However, HSCs in Figure $3 \mathrm{c}$ were cultured in regular DMEM with $10 \%$ of FBS, which inhibited the gene expression of AGE-R1 in HSCs. The difference in media conditions before the treatment could cause a difference in the basal levels of AGE-R1 in the untreated controls in Figure $3 \mathrm{c} v s \mathrm{~b}$ and e. Taken together, our results demonstrated that curcumin eliminated the inhibitory effect of AGEs and induced gene expression of AGE-R1 in passaged HSCs.

\section{Inhibition of ERK Activity Diminished the Effect of AGEs and Induced Gene Expression of AGE-R1 in Cultured HSCs}

To start to elucidate the mechanisms by which curcumin eliminated the effect of AGEs on inhibiting gene expression of AGE-R1 in HSCs, we presumed that AGEs stimulated the activity of ERK in HSCs, leading to the suppression of gene expression of AGE-R1, and that curcumin induced gene expression of AGE-R1 by inhibiting the activity of ERK in HSCs. We have shown that curcumin by itself dose-dependently reduces the level of phosphorylated ERK in cultured HSCs. $^{31}$ Our prior experiments showed that the acute activation of ERK could reach its peak within $20-30 \mathrm{~min}$ in

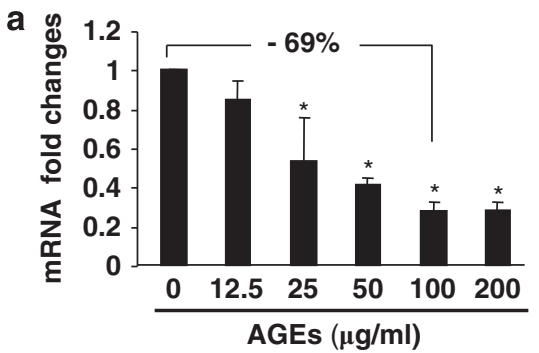

b AGE-R1

$\beta$-tubulin

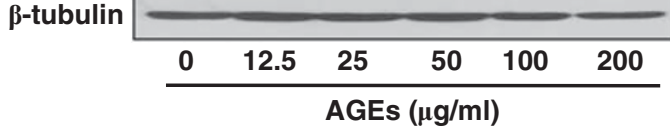

C

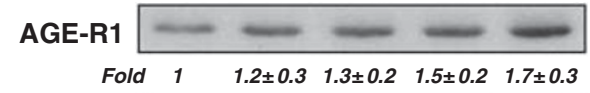

d
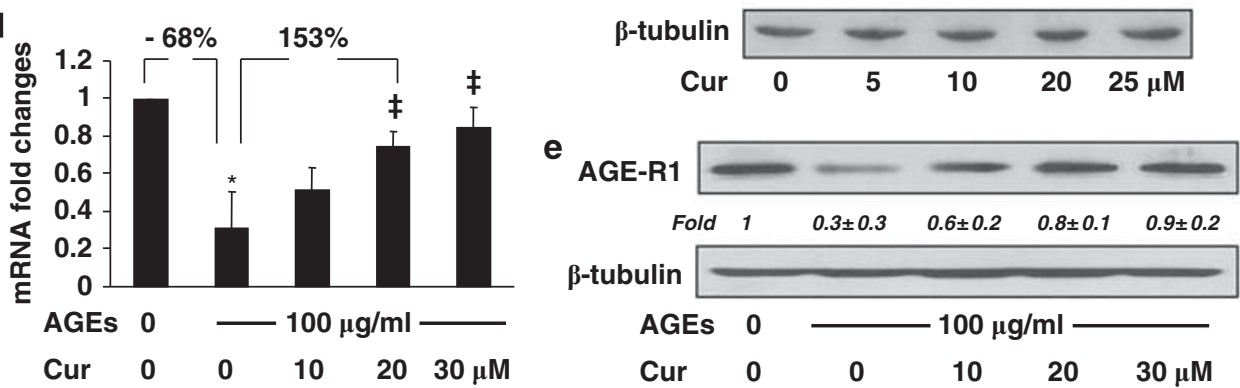

Figure 3 Curcumin abrogated the effect of advanced glycation end-products (AGEs) and induced gene expression of AGE receptor-1 (AGE-R1) in cultured hepatic stellate cells (HSCs). Serum-starved HSCs were treated with AGEs at $0-200 \mu \mathrm{g} / \mathrm{ml}(\mathbf{a}, \mathbf{b})$, or with AGEs at $100 \mu \mathrm{g} / \mathrm{ml}$ plus curcumin at indicated concentrations (d, e), in serum-depleted media for $24 \mathrm{~h}$. On the other hand, passaged HSCs were treated with curcumin at indicated concentrations in Dulbecco's modified Eagle's medium (DMEM) with $10 \%$ fetal bovine serum (FBS) for $24 \mathrm{~h}$ (c). (a, d) Real-time PCR analyses. Values were presented as mRNA fold changes (mean \pm s.d., $n=3$ ). ${ }^{\star} P<0.05$ vs the untreated control (the first column), ${ }^{\ddagger} P<0.05$ vs the cells treated with AGEs alone (the second column). $(\mathbf{b}, \mathbf{c}, \mathbf{e})$ Western blotting analyses. Representatives were from three independent experiments. Then, $\beta$-tubulin was used as an internal control for equal loading. Italic numbers beneath blots were fold changes (means \pm s.d.) in the densities of the bands compared with the control without treatment in the blot $(n=3)$, after normalization with the internal invariable control. 
passaged HSCs after the exposure to stimuli, which was attenuated and inhibited by curcumin. ${ }^{26,32}$ To test our presumption, serum-starved HSCs were treated with AGEs at indicated doses in serum-depleted media for $30 \mathrm{~min} \mathrm{w} / \mathrm{wt}$ the pretreatment with curcumin $(0-30 \mu \mathrm{M})$ for $1 \mathrm{~h}$. Whole-cell extracts were prepared for analyzing levels of phosphorylated ERK. As shown in Figure 4a by western blotting analyses, AGEs caused a dose-dependent increase in the level of phosphorylated ERK, indicating that AGEs indeed induced the activation of ERK in HSCs in vitro. The inductive effect of AGEs on the level of phosphorylated ERK was diminished by curcumin in a dose-dependent manner (Figure $4 \mathrm{~b}$ ).

To evaluate the role of the activation of ERK in regulating gene expression of AGE-R1, serum-starved HSCs were pretreated w/wt the selective ERK inhibitor PD98059 $(0-20 \mu \mathrm{M})$ or curcumin $(20 \mu \mathrm{M})$ for $1 \mathrm{~h}$ before the exposure to AGEs $(100 \mu \mathrm{g} / \mathrm{ml})$ for additional $24 \mathrm{~h}$. Total RNA and whole-cell extracts were prepared from the cells. As shown by real-time PCR (Figure 4c) and western blotting analyses (Figure 4d), compared with the untreated control (the first column and lane), AGEs reduced, as expected, the levels of mRNA and protein of AGE-R1 (the second column and lane). The inhibition of ERK activity by PD98059, mimicking the role of curcumin (the last column and lane), dose-dependently eliminated the inhibitory effect of AGEs and elevated the contents of AGE-R1 mRNA and protein in the cells (the third to fifth columns and lanes). These results collectively supported our presumption and suggested that the stimulation of ERK activity by AGEs might lead to the suppression of gene expression of AGE-R1, which could be abrogated by curcumin by inhibiting the activity of ERK in HSCs.

\section{Alterations in the Activity of ERK Resulted in Changes in the Gene Promoter Activity and the Abundance of AGE- R1 in Cultured HSCs}

To verify the role of the ERK activity in mediating the effect of AGEs on regulating gene expression of AGE-R1, HSCs in six-well culture plates were co-transfected with a DNA mixture, including $2 \mu \mathrm{g}$ of the $A G E-R 1$ gene promoter luciferase reporter plasmid pAGE-R1-Luc, $0.5 \mu \mathrm{g}$ of $\mathrm{pSV}-\beta$-gal and $0.7 \mu \mathrm{g}$ of the cDNA expression plasmid pa-ERK encoding the constitutively a-ERK at various doses plus the empty vector pcDNA, or $1.5 \mu \mathrm{g}$ of the cDNA expression plasmid pdn-ERK encoding the dn-ERK at various doses plus the empty vector pcDNA. The latter was used to ensure equal amount of total DNA in transfection assays. After recovery, cells were serumstarved for $4 \mathrm{~h}$ before the treatment w/wt AGEs $(100 \mu \mathrm{g} / \mathrm{ml})$ in the presence or absence of curcumin $(20 \mu \mathrm{M})$ in serumdepleted media for additional $24 \mathrm{~h}$. Results from luciferase activity assays in Figure $5 \mathrm{a}$ and $\mathrm{b}$ demonstrated that
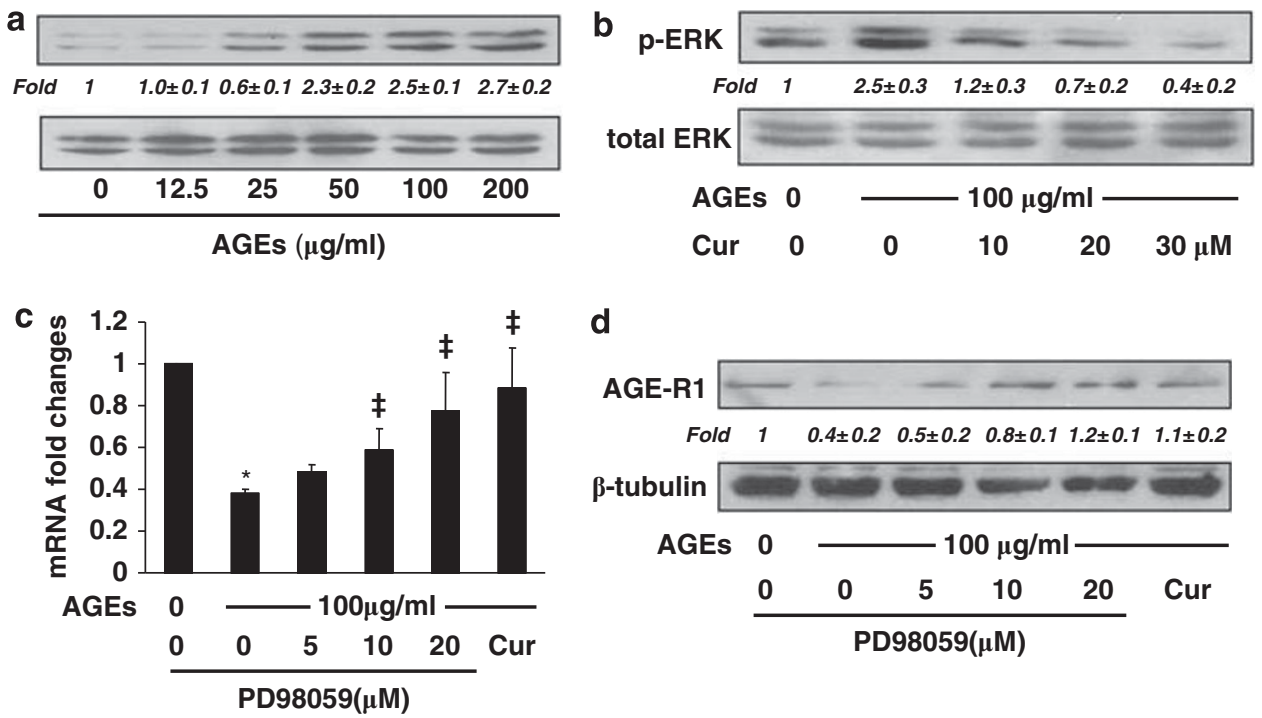

d

AGE-R1

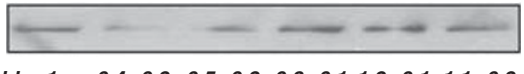

Fold $\quad 1 \quad 0.4 \pm 0.2 \quad 0.5 \pm 0.2 \quad 0.8 \pm 0.1 \quad 1.2 \pm 0.1 \quad 1.1 \pm 0.2$

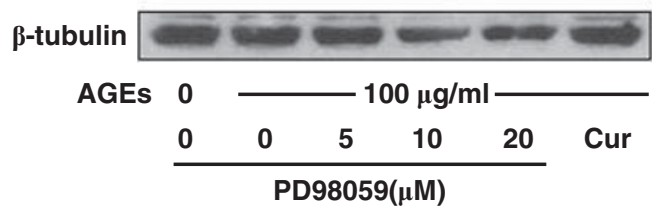

Figure 4 The inhibition of extracellular signal-regulated kinase (ERK) activity diminished the effect of advanced glycation end-products (AGEs) and induced gene expression of AGE receptor-1 (AGE-R1) in cultured hepatic stellate cells (HSCs). (a, b) Serum-starved HSCs were treated with AGEs at indicated doses in serum-depleted media for $30 \mathrm{~min}$ with or without $(\mathrm{w} / \mathrm{wt})$ the pretreatment with curcumin $(0-30 \mu \mathrm{M})$ for $1 \mathrm{~h}$. Whole-cell extracts were prepared for analyzing levels of phosphorylated ERK by western blotting analyses. Total ERK was used as an internal control for equal loading. Italic numbers beneath blots were fold changes (mean \pm s.d., $n=3$ ) in the densities of the bands compared with the control without treatment in the blot, after normalization with the internal invariable control. Representatives were from three independent experiments. (c, d) Serum-starved HSCs were pretreated with or without the selective ERK inhibitor PD98059 $(0-20 \mu \mathrm{M})$ or curcumin $(20 \mu \mathrm{M})$ for $1 \mathrm{~h}$ before the exposure to AGEs $(100 \mu \mathrm{g} / \mathrm{ml})$ for additional $24 \mathrm{~h}$. Total RNA and whole-cell extracts were prepared from the cells. (c) Real-time PCR assays. Values were presented as mRNA fold changes (mean \pm s.d., $n=3$ ). ${ }^{\star} P<0.05$ vs cells with no treatment (the first column). ${ }^{\ddagger} P<0.05$ vs cells treated with AGEs alone (the second column). (d) Western blotting analyses. Then, $\beta$-tubulin was used as an internal control for equal loading. Representatives were from three independent experiments. Italic numbers beneath blots were fold changes (mean \pm s.d., $n=3$ ) in the densities of the bands compared with the control without treatment in the blot, after normalization with the internal invariable control. 
a

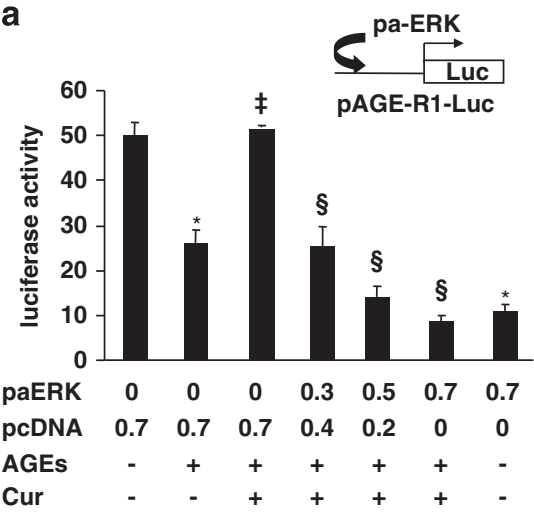

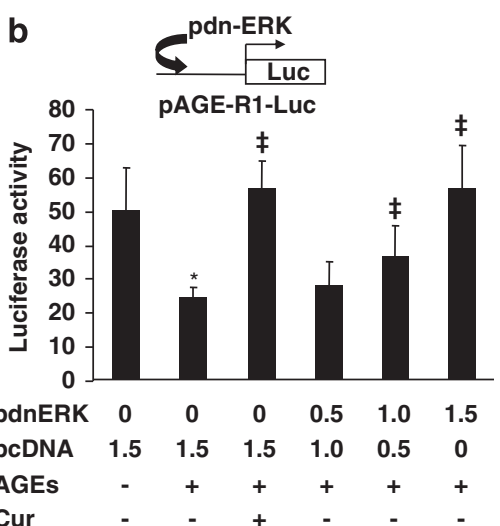

Cur

C

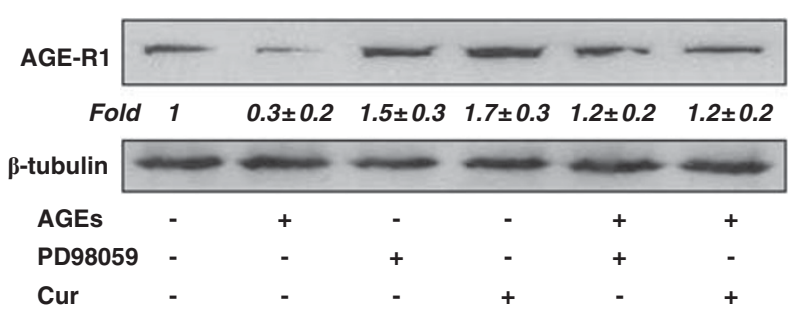

Figure 5 The alterations in the activity of extracellular signal-regulated kinase (ERK) resulted in the changes in the gene promoter activity and the abundance of advanced glycation end-products receptor-1 (AGE-R1) in cultured hepatic stellate cells (HSCs). (a, b) HSCs were co-transfected with the AGER1 promoter luciferase reporter plasmid pAGE-R1-Luc and the CDNA expression plasmid pa-ERK encoding constitutively active ERK (a), or pdn-ERK encoding dominant-negative form of ERK ( $\mathrm{dn}$-ERK; $\mathbf{b}$ ), at indicated doses. After recovery, cells were serum-starved for $4 \mathrm{~h}$ before the treatment with or without (w/wt) AGEs $(100 \mu \mathrm{g} / \mathrm{ml})$ in the presence or absence of curcumin $(20 \mu \mathrm{M})$ in serum-depleted media for additional $24 \mathrm{~h}$. Luciferase activity assays were conducted ( $n=6$ ). ${ }^{\star} P<0.05$ vs cells with no treatment (the first column). ${ }^{\ddagger} P<0.05$ vs cells treated with AGEs alone (the second column). ${ }^{\S} p<0.05$ vs cells treated with AGEs plus curcumin (the third column). The floating schema denoted the plasmids PAGE-R1-Luc and pa-ERK, or pdn-ERK in use for co-transfection. (c) Serum-starved HSCs were treated with AGEs $(100 \mu \mathrm{g} / \mathrm{ml})$ in the presence of curcumin $(20 \mu \mathrm{M})$, or the ERK selective inhibitor PD98059 $(10 \mu \mathrm{M})$, in serumdepleted media for $24 \mathrm{~h}$. Western blotting analyses were conducted. Then, $\beta$-tubulin was used as an internal control for equal loading. Representatives were from three independent experiments. Italic numbers beneath blots were fold changes (mean \pm s.d., $n=3$ ) in the densities of the bands compared with the control without treatment in the blot, after normalization with the internal invariable control.

compared with the untreated control (the corresponding first column), AGEs significantly reduced, as expected, the luciferase activity in the cells, indicating a reduction in the promoter activity of the AGE-R1 gene (the corresponding second column). Curcumin apparently eliminated the inhibitory effect of AGEs on the gene promoter activity AGER1 (the corresponding third column). It was further observed that forced expression of exogenous active ERK cDNA dosedependently diminished the role of curcumin and reduced luciferase activities in the cells (the fourth to sixth columns in Figure 5A). Compared with the control (the first column), the co-transfection of pa-ERK alone, as a control, significantly reduced the luciferase activity in the cells (the last column in Figure 5a). These results confirmed that the increase in ERK activity could reduce the gene promoter activity of AGE-R1 in HSCs. In contrast, forced expression of exogenous dn-ERK cDNA diminished the effect of AGEs and increased, like curcumin (the third column in Figure 5b), the luciferase activities in a dose-dependent manner (the fourth to sixth columns in Figure 5b), indicating that the blockade of the ERK signaling pathway by dn-ERK abrogated the effect of AGEs on the inhibition of the promoter activity of the AGE-R1 gene.
To further confirm the role of the curcumin-caused inhibition of ERK in the upregulation of expression of AGE-R1, serum-starved HSCs were treated with AGEs $(100 \mu \mathrm{g} / \mathrm{ml})$ in the presence of curcumin $(20 \mu \mathrm{M})$, or the ERK selective inhibitor PD98059 $(10 \mu \mathrm{M})$ in serumdepleted media for $24 \mathrm{~h}$. Western blotting analyses indicated that compared with the untreated control (the first lane), AGEs reduced, as expected, the abundance of AGE-R1 in HSCs (the second lane). It is of interest to observe that the ERK inhibitor PD98059 (the fifth lane) mimicked the role of curcumin (the sixth lane) in the attenuation of the inhibitory effect of AGEs and in the elevation of the level of AGE-R1 in HSCs. PD98059 (the third lane) or curcumin (the fourth lane) alone showed the effect on the elevation of the level of AGE-R1 in serumstarved HSCs. Taken together, our results indicated that the alterations in the activity of ERK resulted in the changes in the gene promoter activity of AGE-R1 and in the abundance of AGE-R1 in cultured HSCs. Our results also revealed a critical role of the curcumin-caused inhibition of ERK in the upregulation of expression of AGE-R1. 


\section{AGEs Suppressed Gene Expression of PPAR $y$ and Reduced its Transactivity in HSCs, which were Diminished by Curcumin}

PPAR $\gamma$ is highly expressed in quiescent HSCs in the normal liver. ${ }^{33}$ However, the level of $\operatorname{PPAR} \gamma$ and its activity are dramatically reduced during the process of HSC activation in vitro and in vivo. ${ }^{33}$ We previously reported that curcumin induced gene expression of PPAR $\gamma$ in vitro and in vivo, ${ }^{15-17}$ which was required for curcumin to inhibit HSC activation in vitro. ${ }^{16,17}$ To further elucidate the underlying mechanisms by which curcumin eliminated the effect of AGEs and induced gene expression of AGE-R1 in HSCs, we assumed that AGEs suppressed gene expression of PPAR $\gamma$ in HSCs, which was abolished by curcumin. To test the assumption, serumstarved HSCs were stimulated w/wt AGEs $(100 \mu \mathrm{g} / \mathrm{ml})$ in the presence of curcumin $(0-30 \mu \mathrm{M})$ in serum-depleted media for $24 \mathrm{~h}$. Total RNA and whole-cell extracts were prepared from the cells. As shown by real-time PCR (Figure 6a) and western blotting analyses (Figure 6b), compared with the untreated control (the first column and lane), AGEs significantly reduced gene expression of $\operatorname{PPAR} \gamma$ (the second column and lane). The inhibitory effect of AGEs was dosedependently diminished by curcumin (the third to fifth columns and lanes).

To evaluate the effect of AGEs on the transactivity of $\operatorname{PPAR} \gamma$, HSCs were transfected with the PPAR $\gamma$ activity luciferase reporter plasmid pPPRE-Luc. After recovery, cells were serum-starved for $4 \mathrm{~h}$ before the treatment w/wt AGEs $(100 \mu \mathrm{g} / \mathrm{ml})$ in the presence of curcumin $(0-30 \mu \mathrm{M})$ in serum-depleted media with $\mathrm{PGJ}_{2}(5 \mu \mathrm{M})$ for additional $24 \mathrm{~h}$. The exogenous PPAR $\gamma$ agonist $\mathrm{PGJ}_{2}$ was added, because there was no PPAR $\gamma$ agonist in serum-depleted media. Results from luciferase activity assays indicated that compared with the untreated control (the first column), AGEs reduced luciferase activity by $59 \%$ (the second column), suggesting a significant reduction in the transactivity of PPAR $\gamma$ in the cells. The inhibitory effect of AGEs was dose-dependently eliminated by curcumin (the third to fifth columns). These results collectively demonstrated that AGEs suppressed gene expression of $\operatorname{PPAR} \gamma$ and reduced its transactivity in HSCs, which were diminished by curcumin by inducing gene expression of $\operatorname{PPAR} \gamma$.

\section{Activation of PPAR $\gamma$ Eliminated the Inhibitory Effect of AGEs and Stimulated Gene Expression of AGE-R1 in HSCs In Vitro}

To evaluate the role of the activation of PPAR $\gamma$ in regulating the gene promoter activity of AGE-R1, HSCs were transfected with the AGE-R1 gene promoter luciferase reporter plasmid pAGE-R1-Luc. After recovery, cells were serum-starved for $4 \mathrm{~h}$ before the treatment w/wt AGEs $(100 \mu \mathrm{g} / \mathrm{ml})$ in the presence or absence of the natural PPAR $\gamma$ agonist $\mathrm{PGJ}_{2}$, or the synthesized PPAR $\gamma$ agonist rosiglitazone (Rosi), at $0-10 \mu \mathrm{M}$ in serum-depleted media for additional $24 \mathrm{~h}$. Results from the luciferase activity assays in Figure $7 \mathrm{a}$ demonstrated that
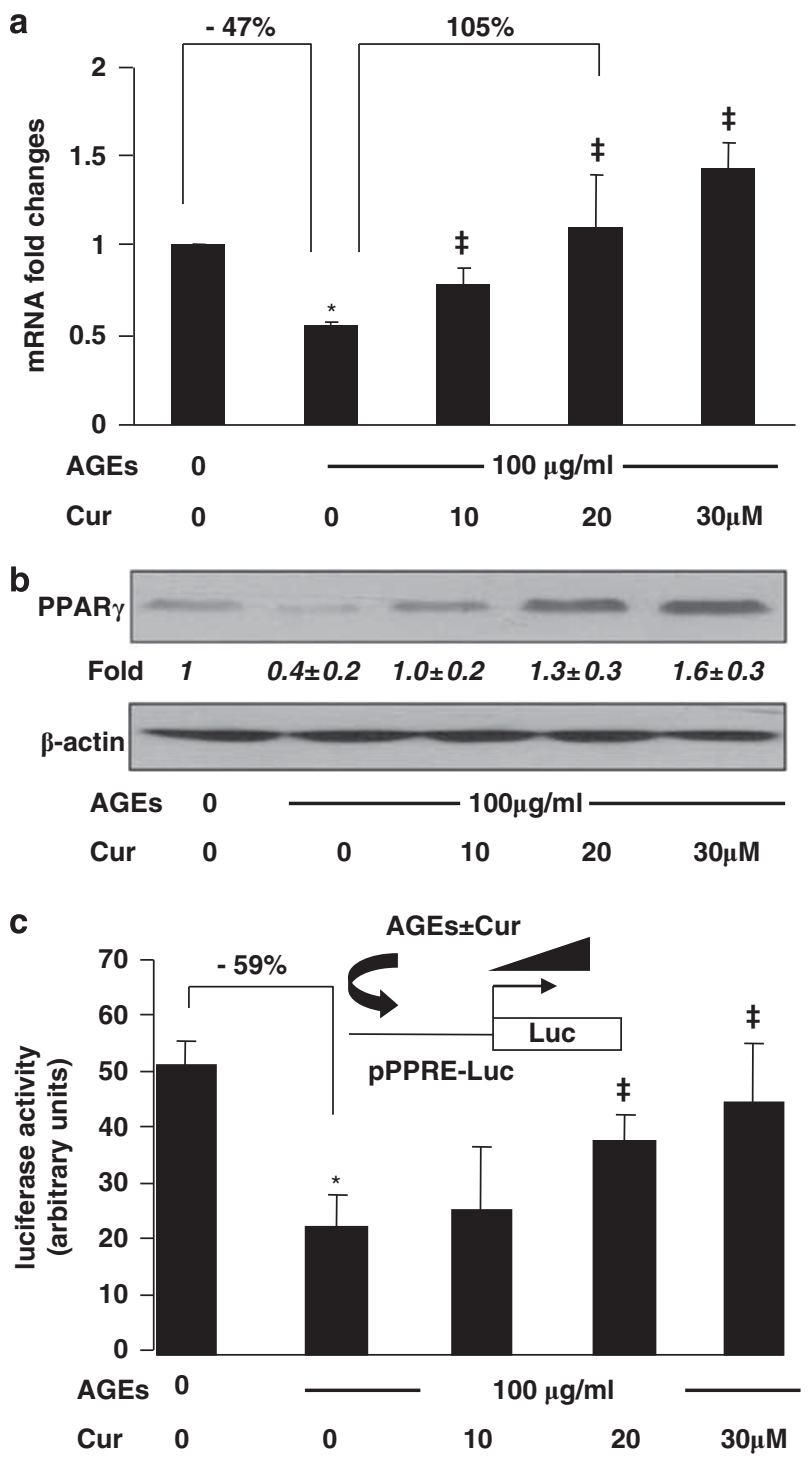

Figure 6 Advanced glycation end-products (AGEs) suppressed gene expression of peroxisome proliferator-activated receptor-gamma (PPAR $\gamma$ ) and reduced its transactivity in hepatic stellate cells (HSCs), which were diminished by curcumin. $(\mathbf{a}, \mathbf{b})$ Serum-starved HSCs were stimulated with or without (w/wt) AGEs $(100 \mu \mathrm{g} / \mathrm{ml})$ in the presence of curcumin $(0-30 \mu \mathrm{M})$ in serum-depleted media for $24 \mathrm{~h}$. Total RNA and whole-cell extracts were prepared. (a) Real-time PCR assays. Values were presented as mRNA fold changes (mean \pm s.d., $n=3$ ). ${ }^{\star} P<0.05$ vs cells with no treatment (the first column). ${ }^{\ddagger} P<0.05$ vs cells treated with AGEs alone (the second column). (b) Western blotting analyses. Then, $\beta$-actin was used as an internal control for equal loading. Representatives were from three independent experiments. Italic numbers beneath blots were fold changes (mean \pm s.d., $n=3$ ) in the densities of the bands compared with the control without treatment in the blot, after normalization with the internal invariable control. (c) HSCs were transfected with the PPAR $\gamma$ activity luciferase reporter plasmid pPPRE-Luc. After recovery, cells were serum-starved for $4 \mathrm{~h}$ before the treatment with or without (w/wt) AGEs $(100 \mu \mathrm{g} / \mathrm{ml})$ in the presence of curcumin $(0-30 \mu \mathrm{M})$ in serum-depleted media with prostaglandin $\mathrm{J}_{2}\left(\mathrm{PGJ}_{2} ; 5 \mu \mathrm{M}\right)$ for $24 \mathrm{~h}$. Luciferase activity assays were conducted $(n=6)$. ${ }^{*} P<0.05$ vs cells with no treatment (the first column), ${ }^{\ddagger} P<0.05$ vs cells treated with AGEs alone (the second column). The floating schema denoted the plasmid pPPRE-Luc in use for transfection and the application of AGEs w/wt curcumin to the system. 

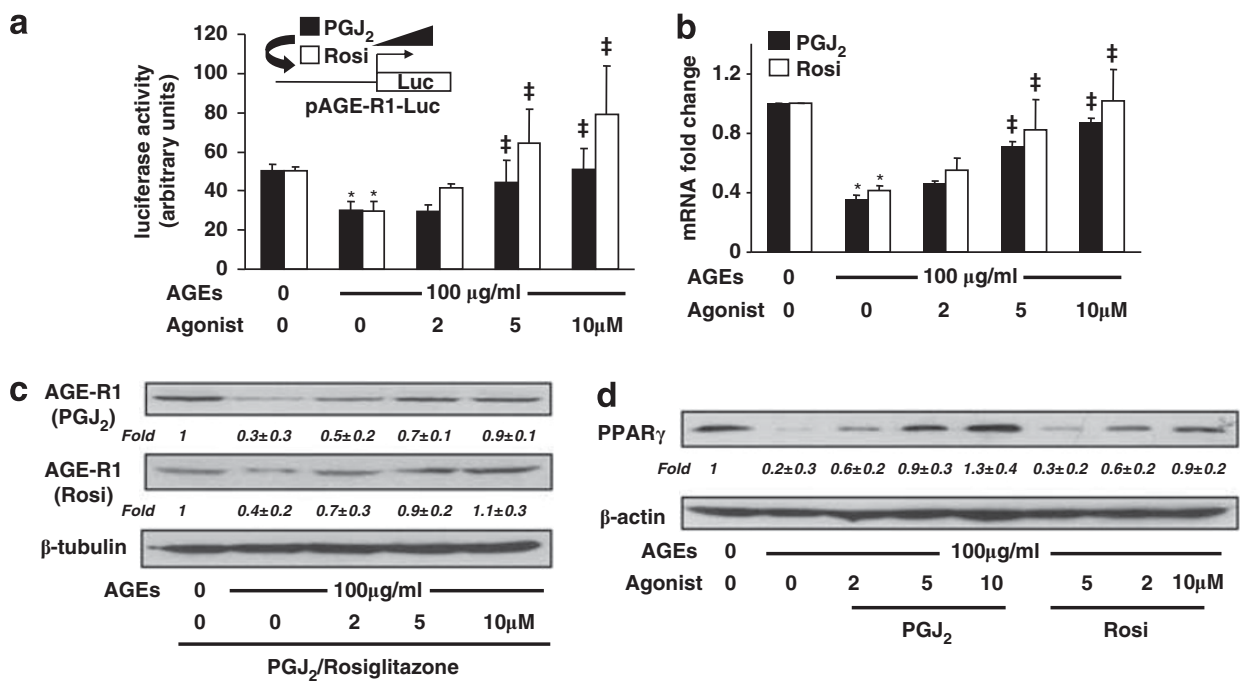

Figure 7 The activation of peroxisome proliferator-activated receptor-gamma (PPAR $\gamma$ ) eliminated the inhibitory effect of advanced glycation end-products (AGEs) and stimulated gene expression of AGE receptor-1 (AGE-R1) in hepatic stellate cells (HSCs) in vitro. (a) HSCs were transfected with the AGE-R1 promoter luciferase reporter plasmid pAGE-R1-Luc. After recovery, cells were serum-starved for $4 \mathrm{~h}$ before the treatment with or without (w/wt) AGEs $(100 \mu \mathrm{g} / \mathrm{ml})$ in the presence of prostaglandin $\mathrm{J}_{2}\left(\mathrm{PGJ}_{2}\right)$, or rosiglitazone (Rosi), at $0-10 \mu \mathrm{M}$ in serum-depleted media for $24 \mathrm{~h}$. Luciferase activity assays were conducted $(n=6)$. ${ }^{\star} P<0.05$ vs cells with no treatment (the corresponding first column). ${ }^{\ddagger} P<0.05$ vs cells treated with AGEs alone (the corresponding second column). The floating schema denoted pAGE-R1-Luc in use for transfection and the application of PGJ , $_{2}$ or Rosi, to the system. (b-d) Serum-starved HSCs were stimulated w/wt AGEs $(100 \mu \mathrm{g} / \mathrm{ml})$ in the presence of $\mathrm{PGJ}_{2}$ or Rosi, at $0-10 \mu \mathrm{M}$ in serum-depleted media for $24 \mathrm{~h}$. Total RNA and whole-cell extracts were prepared. (b) Real-time PCR assays. Values were presented as mRNA fold changes (mean \pm s.d., $n=3$ ). ${ }^{\star} P<0.05$ vs cells with no treatment (the corresponding first column). ${ }^{\ddagger} P<0.05$ vs cells treated with AGEs alone (the corresponding second column). (c, d) Western blotting analyses. Then, $\beta$-tubulin or $\beta$-actin was used as an internal control for equal loading. Representatives were from three independent experiments. Italic numbers beneath blots were fold changes (mean \pm s.d., $n=3$ ) in the densities of the bands compared with the control without treatment in the blot, after normalization with the internal invariable control.

compared with the untreated control (the corresponding first column), AGEs significantly reduced, as expected, the luciferase activity in the cells (the corresponding second column). The inhibitory effect of AGEs was dose-dependently abrogated by either $\mathrm{PGJ}_{2}$ or Rosi (the corresponding third to fifth columns), suggesting that the activation of PPAR $\gamma$ eliminated the inhibitory effect of AGEs on the gene promoter activity of AGE-R1 in passaged HSCs.

To verify the role of the activation of PPAR $\gamma$ in inducing gene expression of AGE-R1, serum-starved HSCs were stimulated w/wt AGEs $(100 \mu \mathrm{g} / \mathrm{ml})$ in the presence of the $\operatorname{PPAR} \gamma$ agonist $\mathrm{PGJ}_{2}$, or Rosi at $0-10 \mu \mathrm{M}$ in serum-depleted media for $24 \mathrm{~h}$. Results from real-time PCR (Figure $7 \mathrm{~b}$ ) and western blotting analyses (Figure 7c) demonstrated that the activation of PPAR $\gamma$ by $\mathrm{PGJ}_{2}$ or Rosi eliminated the inhibitory effect of AGEs and dose-dependently induced gene expression of AGE-R1 at the levels of transcript and protein in the cells (the corresponding third to fifth columns and lanes).

Additional experiments were conducted to address the question whether the stimulation of the AGE-R1 gene expression in HSCs by $\mathrm{PGJ}_{2}$ or Rosi corresponded to an increase in PPAR $\gamma$. HSCs were treated w/wt AGEs $(100 \mu \mathrm{g} / \mathrm{ml})$ in the presence of $\mathrm{PGJ}_{2}$, or Rosi at $0-10 \mu \mathrm{M}$ in serumdepleted media for $24 \mathrm{~h}$. Western blotting analyses in Figure $7 \mathrm{~d}$ demonstrated that $\mathrm{PGJ}_{2}$ or Rosi, mimicking the role of curcumin
(Figure 6b), dose-dependently eliminated the effect of AGEs on the level of PPAR $\gamma$ in HSCs in vitro. To our knowledge, the role of the PPAR $\gamma$ agonist $\mathrm{PGJ}_{2}$, or Rosi, in inducing gene expression of PPAR $\gamma$ in HSCs has never been reported. Taken together, our results demonstrated that the activation of PPAR $\gamma$ eliminated the inhibitory effect of AGEs and stimulated gene expression of AGE-R1 in HSCs in vitro.

\section{Stimulation of the Transactivity of PPAR $\gamma$ had a Critical Role in the Curcumin-Caused Elimination of the Effect of AGEs on the Inhibition of Gene Expression of AGE-R1 in HSCs In Vitro}

To further evaluate the role of the activation of PPAR $\gamma$ in the curcumin-caused elimination of the inhibitory effect of AGEs on gene expression of AGE-R1, serum-starved HSCs were pretreated w/wt the PPAR $\gamma$ antagonist PD $(20 \mu \mathrm{M})$ for $30 \mathrm{~min}$ before the exposure to AGEs $(100 \mu \mathrm{g} / \mathrm{ml})$, or curcu$\min (20 \mu \mathrm{M})$, or both, in serum-depleted media with $\mathrm{PGJ}_{2}$ $(5 \mu \mathrm{M})$ for additional $24 \mathrm{~h}$. Total RNA and whole-cell extracts were prepared for real-time PCR (Figure 8a) and western blotting analyses (Figure 8b). Compared with the untreated control (the first column and lane), AGEs significantly reduced the levels of mRNA and protein of AGE-R1 in the cells (the second column and lane). Curcumin, as expected, dramatically eliminated the effect of AGEs and increased the contents of mRNA and protein of AGE-R1 (the third column 

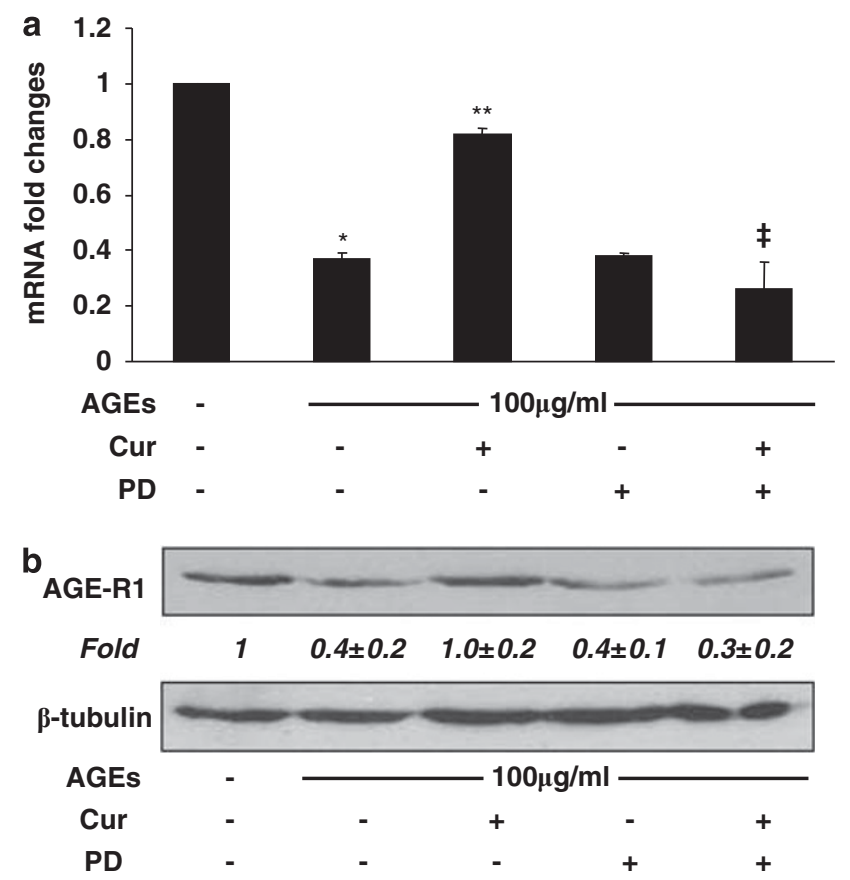

Figure 8 The stimulation of the transactivity of peroxisome proliferatoractivated receptor-gamma (PPAR $\gamma$ ) had a critical role in the curcumincaused elimination of the effect of advanced glycation end-products (AGEs) on inhibiting gene expression of AGE receptor-1 (AGE-R1) in hepatic stellate cells (HSCs) in vitro. Serum-starved HSCs were pretreated w/wt the PPAR $\gamma$ antagonist PD68235 (PD; $20 \mu \mathrm{M}$ ) for 30 min before the exposure to AGEs $(100 \mu \mathrm{g} / \mathrm{ml})$ or curcumin $(20 \mu \mathrm{M})$, or both, in serum-depleted media with prostaglandin $\mathrm{J}_{2}\left(\mathrm{PGJ}_{2} ; 5 \mu \mathrm{M}\right)$ for additional $24 \mathrm{~h}$. Total RNA and whole-cell extracts were prepared. (a) Real-time PCR assays. Values were presented as mRNA fold changes (mean \pm s.d., $n=3$ ). ${ }^{*} P<0.05$ vs cells with no treatment (the first column); ${ }^{* *} P<0.05$ vs cells treated with AGEs alone (the second column); ${ }^{\ddagger} P<0.05$ vs cells treated with both AGEs and curcumin (the third column). (b) Western blotting analyses. Then, $\beta$-tubulin was used as an internal control for equal loading. Representatives were shown from three independent experiments. Italic numbers beneath blots were fold changes (mean \pm s.d., $n=3$ ) in the densities of the bands compared with the control without treatment in the blot, after normalization with the internal invariable control.

and lane). It was of interest to observe that the blockade of $\operatorname{PPAR} \gamma$ activation by the pretreatment with the $\operatorname{PPAR} \gamma$ antagonist PD apparently attenuated the role of curcumin in eliminating the inhibitory effect of AGEs (the last column and lane), suggesting a critical role of the activity of PPAR $\gamma$ in the process. PD alone had no apparent effect (the fourth column and lane). These results collectively indicated that the stimulation of the transactivity of PPAR $\gamma$ had a critical role in the curcumin-caused elimination of the effect of AGEs on the inhibition of gene expression of AGE-R1 in HSCs in vitro.

\section{ERK and PPAR $\gamma$ Acted Sequentially in the Attenuation of the Effect of AGEs on the Regulation of the Expression of AGE-R1 in HSCs}

To elucidate the relationship between the ERK signaling pathway and the activation of $\operatorname{PPAR} \gamma$ in regulating gene expression of AGE-R1, passaged HSCs in six-well plates were co-transfected with a total of $4.5 \mu \mathrm{g}$ of a DNA mixture per well, including $2 \mu \mathrm{g}$ of the promoter activity luciferase reporter plasmid pAGE-R1-Luc, $0.5 \mu \mathrm{g}$ of pSV- $\beta$-gal, and $2 \mu \mathrm{g}$ of the cDNA expression plasmid pa-ERK, encoding constitutively active ERK, at indicated doses plus the empty vector pcDNA. The latter was used to ensure an equal amount of total DNA in transfection assays. After overnight recovery from transfection, cells were serum-starved for $4 \mathrm{~h}$ before the treatment w/wt AGEs $(100 \mu \mathrm{g} / \mathrm{ml})$ in the presence or absence of $\mathrm{PGJ}_{2}(5 \mu \mathrm{M})$ in serum-depleted media for additional $24 \mathrm{~h}$. As shown in Figure 9, compared with the untreated control (the first column), AGEs significantly reduced, as expected, luciferase activity in cells transfected with pAGE-R1-Luc (the second column). Forced expression of constitutively active ERK potentiated the inhibitory effect of AGEs (the third column). On the other hand, the activation of PPAR $\gamma$ with $\mathrm{PGJ}_{2}$ dramatically diminished the inhibitory effect of AGEs (the fourth column). It was of interest to observe that forced expression of constitutively active ERK eliminated the role of $\mathrm{PGJ}_{2}$ and reduced luciferase activities in a dose-dependent manner (the fourth to seventh columns), indicating that the activation of the ERK signaling pathway counteracted the role of PPAR $\gamma$ activation in stimulating the promoter activity of AGE-R1. This result suggested a sequential relationship between ERK and PPAR $\gamma$ in regulating the promoter activity of AGE-R1 in HSCs.

To further elucidate the relationship between ERK and PPAR $\gamma$ in the attenuation of the inhibitory effect of AGEs on the regulation of gene expression of AGE-R1, serum-starved HSCs were treated with AGEs $(100 \mu \mathrm{g} / \mathrm{ml})$ and the PPAR $\gamma$ agonist $\mathrm{PGJ}_{2}(5 \mu \mathrm{M})$ plus or minus the ERK selective inhibitor PD98059 $(10 \mu \mathrm{M})$ in serum-depleted media for $24 \mathrm{~h}$. Western blotting analyses in Figure 9b revealed that compared with the untreated cells (the first lane), $\mathrm{PGJ}_{2}$ by itself increased the level of AGE-R1 (the fifth lane). AGEs significantly reduced the level of AGE-R1 in HSCs (the second lane), which was dramatically attenuated, as expected, by the activation of PPAR $\gamma$ by $\mathrm{PGJ}_{2}$ (the third lane). It was further shown that the presence of PD98059 strengthened the role of $\mathrm{PGJ}_{2}$ in the attenuation of the inhibitory effect of AGEs on the expression of AGE-R1 in HSCs (the fourth lane). Taken together, our results suggested a sequential relationship between upstream ERK and downstream PPAR $\gamma$ in the attenuation of the effect of AGEs on the regulation of the expression of AGE-R1 in HSCs.

\section{DISCUSSION}

The development of T2DM is coupled with the increase in the levels of many detrimental factors, some of which stimulate the activation of HSCs, including hyperinsulinemia, ${ }^{26}$ hyperleptinemia, ${ }^{34}$ dyslipidemia $^{35,36}$ and hyperglycemia. ${ }^{37}$ Our present study provided the evidence that AGEs, whose formation is facilitated and stimulated by hyperglycemia, were an additional stimulus for inducing HSC activation. 
a
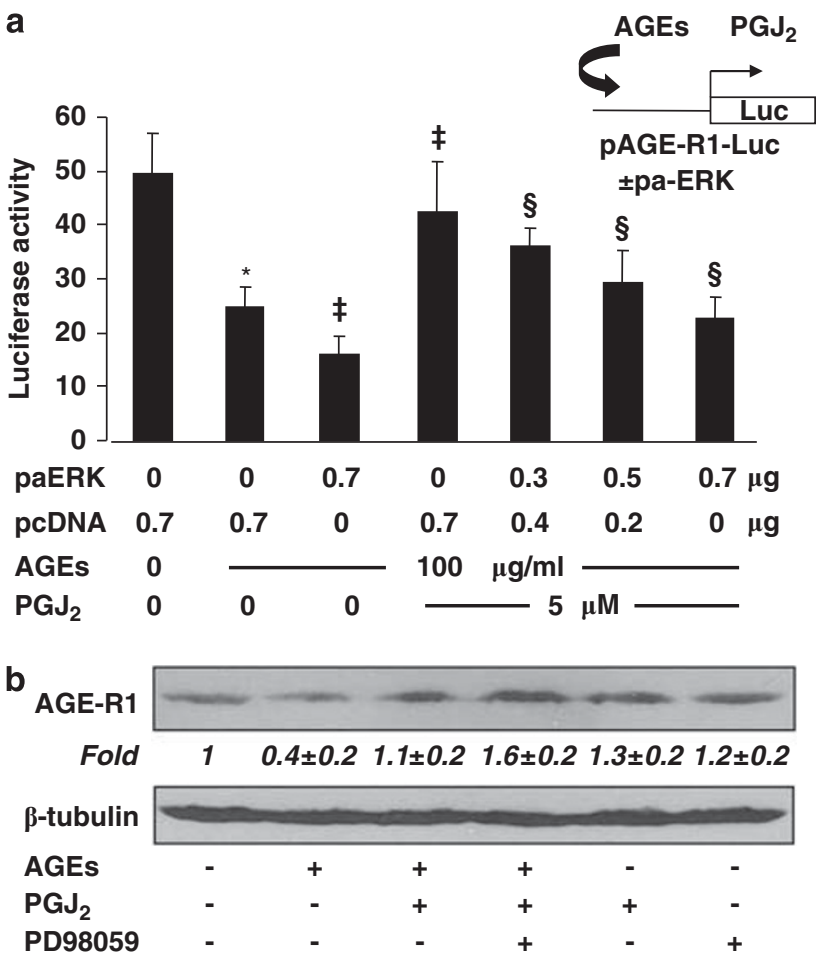

Figure 9 Extracellular signal-regulated kinase (ERK) and peroxisome proliferator-activated receptor-gamma (PPAR $\gamma$ ) acted sequentially in the attenuation of the effect of advanced glycation end-products (AGEs) on the regulation of the expression of AGE receptor-1 (AGE-R1) in hepatic stellate cells (HSCs). (a) Passaged HSCs in six-well plates were co-transfected with a total of $4.5 \mu \mathrm{g}$ of a DNA mixture per well, including $2 \mu \mathrm{g}$ of the promoter activity luciferase reporter plasmid pAGE-R1-Luc, $0.5 \mu \mathrm{g}$ of pSV- $\beta$-gal and $2 \mu \mathrm{g}$ of the cDNA expression plasmid pa-ERK, encoding constitutively active ERK, at indicated doses plus the empty vector pcDNA. The latter was used to ensure an equal amount of total DNA in transfection assays. After overnight recovery, cells were serum-starved for $4 \mathrm{~h}$ before the treatment with or without (w/wt) AGEs $(100 \mu \mathrm{g} / \mathrm{ml})$ in the presence or absence of the PPAR $\gamma$ agonist prostaglandin $J_{2}\left(\mathrm{PGJ}_{2} ; 5 \mu \mathrm{M}\right)$ in serum-depleted media for additional $24 \mathrm{~h}$. Luciferase activity assays were conducted $(n=6) .{ }^{\star} P<0.05$ vs cells with no treatment (the first column); ${ }^{\ddagger} P<0.05$ vs cells treated with AGEs alone (the second column); ${ }^{{ }} P<0.05$ vs cells transfected with no pa-ERK, but treated with both AGEs and $P G J_{2}$ (the fourth column). The floating schema denoted pAGE-R1-Luc in use w/wt pa-ERK for co-transfection, and the application of AGEs w/wt PGJ $J_{2}$ to the system. (b) Serum-starved HSCs were treated with AGEs $(100 \mu \mathrm{g} / \mathrm{ml})$, and the PPAR $\gamma$ agonist PGJ $(5 \mu \mathrm{M})$ plus or minus the ERK selective inhibitor PD98059 $(10 \mu \mathrm{M})$ in serumdepleted media for $24 \mathrm{~h}$. Western blotting analyses were conducted. Then, $\beta$-tubulin was used as an internal control for equal loading. Representatives were from three independent experiments. Italic numbers beneath blots were fold changes (mean \pm s.d., $n=3$ ) in the densities of the bands compared with the control without treatment in the blot, after normalization with the internal invariable control.

AGE-R1 has been reported to have functions in detoxification and clearance of AGEs. ${ }^{7}$ The current study was designed to evaluate effects of AGEs on inducing HSC activation, to assess the role of curcumin in diminishing the AGE effects, and to explore the underlying mechanisms. We observed that AGEs induced the activation of HSCs and suppressed gene expression of AGE-R1 in activated HSCs. The phytochemical curcumin eliminated the effects of AGEs and induced gene expression of AGE-R1 likely by inhibiting the ERK activity and stimulating the transactivity of PPAR $\gamma$.

AGEs elicit their effects via receptors. Although AGE-R1 and other receptors, including CD36 and Scr-II, assist AGE clearance, RAGE facilitates pro-inflammation. ${ }^{7,38}$ The AGEsRAGE-OS axis is involved in diabetic complications. ${ }^{3}$ A dramatic increase in RAGE expression is found in diabetic patients with high levels of plasma AGEs. ${ }^{8,39}$ On the other hand, the AGE-R1 abundance is significantly reduced in diabetic kidney, ${ }^{9}$ suggesting a possible inverse relationship between AGEs-mediated cell injury and low expression of AGE-R1. Overexpression of AGE-R1 reduces basal levels of AGEs and OS, enhances resistance to hyperglycemia and protects against inflammation in vivo. ${ }^{40}$ Inhibition of AGE formation, blockade of AGEs-RAGE interaction, suppression of RAGE expression, interruption of its signaling and induction of AGE-R1 expression are, thus, novel therapeutic strategies for treatment of diabetic complications. ${ }^{41}$ To our knowledge, this study is the first report to observe that AGEs suppressed gene expression of AGE-R1 in passaged HSCs, which could be eliminated by curcumin. Prior studies suggested that AGE-R1 might be a negative regulator in the inflammatory response to AGEs in mesangial cells. ${ }^{7}$ It was also reported that an increase in the dietary AGE contents reduced the ratio of AGE-R1 to RAGE in cells, leading to an increase in OS and organ damage, and a reduction in life span. ${ }^{42}$ In addition to the induction of gene expression of AGE-R1 in HSCs, our preliminary results also suggested that curcumin inhibited gene expression of RAGE in HSCS in vitro (data not shown). Additional experiments are ongoing in our lab to elucidate molecular mechanisms by which curcumin divergently regulated gene expression of RAGE and AGE-R1 in HSCs.

OS induces HSC activation and hepatic fibrogenesis. ${ }^{10}$ Studies have suggested that AGE-R1 is not only a scavenger receptor that facilitates uptake and degradation of AGEs, but also a receptor mediating the attenuation of OS. ${ }^{43}$ Therefore, the curcumin-caused induction of gene expression of AGER1 could attenuate OS in passaged HSCs, leading to the inhibition of the AGEs-induced activation of HSCs. On the other hand, curcumin itself is a potent antioxidant, whose antioxidant capacity is 100 -fold stronger than that of vitamin $\mathrm{E} / \mathrm{C},{ }^{44}$ likely by inducing gene expression of glutamatecysteine ligase, a key rate-limiting enzyme in de novo synthesis of glutathione. ${ }^{18}$ It is plausible to assume that in addition to the induction of the $A G E-R 1$ gene expression, curcumin itself could attenuate OS, which also facilitates the inhibition of the AGEs-induced activation of HSCs.

As demonstrated in the report, AGEs inhibited gene expression of AGE-R1, which could be diminished by the activation of PPAR $\gamma$ by $\mathrm{PGJ}_{2}$ or Rosi (Figure 7c). It was explained that a portion of the stimulatory role of $\mathrm{PGJ}_{2}$ might be used to counteract the inhibitory effect of AGEs. Therefore, the effect of $\mathrm{PGJ}_{2}$ alone on elevating the level of 
AGE-R1 was more prominent than that of the treatment with both $\mathrm{PGJ}_{2}$ and AGEs (Figure 9b). On the other hand, our results could not exclude other possible mechanisms by which the activation of PPAR $\gamma$ by $\mathrm{PGJ}_{2}$ elevated the abundance of AGE-R1, including increasing the protein stability and/or mRNA half-life of AGE-R1 in HSCs in vitro.

Our results in this report indicated that AGEs stimulated the activation of ERK, suppressed gene expression of PPAR $\gamma$ and reduced its transactivation activity in activated HSCs in vitro. Our results also suggested a sequential relationship between upstream ERK and downstream PPAR $\gamma$ in the attenuation of the effect of AGEs on the regulation of the expression of AGE-R1 in HSCs. Our observations were in agreement with prior other reports. ${ }^{45,46}$ The activation of mitogen-activated protein kinase signaling pathways stimulates the phosphorylation of $\operatorname{PAAR} \gamma$, resulting in a reduction in the transactivation activity of the nuclear transcription factor. ${ }^{45,46}$ We demonstrated that curcumin inhibited the activity of ERK and induced gene expression of PPAR $\gamma$ in passaged HSCs, ${ }^{16,17}$ both of which attenuated the inhibitory effects on the promoter activity of AGE-R1 in HSCs. It is, therefore, understandable that curcumin could eliminate the effect of AGEs and induce gene expression of AGE-R1 in HSCs. It is worth mentioning that the pharmacological approach, ie, using the selective ERK inhibitor, might not be the best, but a proper one, to address the questions studied in this report. Additional experiments are necessary to elucidate the underlying molecular mechanisms of the PPAR $\gamma$-dependent ERK signaling pathway in regulating the promoter activity of AGE-R1 in HSCs. However, it is noteworthy that our results did not exclude possible PPAR $\gamma$-independent effects of the ERK pathway on inhibiting the promoter activity of AGE-R1 in HSCs.

The toxicity of curcumin to cultured HSCs was previously evaluated. ${ }^{16}$ On the basis of the results from lactate dehydrogenase release assays, trypan blue exclusion assays and a rapid recovery of cell proliferation after withdrawal of curcumin, it was concluded that curcumin up to $100 \mu \mathrm{M}$ was not toxic to cultured HSCs. Curcumin at $20 \mu \mathrm{M}$ was used in most of our in vitro experiments. The systemic bioavailability of curcumin is relatively low. ${ }^{47}$ Curcumin concentrations in human plasma can reach up to $2 \mu \mathrm{M}$, following oral intake of very high amounts of curcumin. ${ }^{48}$ Few reports could be found regarding serum levels of the AGE proteins in human populations w/wt diabetes. Among these limited studies, the levels of serum AGEs in human were not consistent. ${ }^{49-53}$ AGEs at $100 \mu \mathrm{g} / \mathrm{ml}$ was used in most of the experiments in this project. The same dose of human glycated albumin was also used to examine its effects on insulin signaling in L6 skeletal muscle cells. ${ }^{24}$ The concentration of AGEs used in our experiments was determined by measuring AGEs-specific fluorescence with excitation at $360 \mathrm{~nm}$ and emissions at $440 \mathrm{~nm}^{22,23} \mathrm{~N}$-carboxymethyl-lysine (CML) was a major AGE among them. ${ }^{22,23}$ The level of CML was previously observed to be higher in diabetic patients than non-diabetic controls. ${ }^{51}$ It is noteworthy that because the in vivo system is multifactorial, directly extrapolating in vitro conditions and results, eg, effective concentrations, to the in vivo system, or vice versa, might be misleading.

Prior studies showed the role of curcumin in inhibiting the AGEs-induced increase in NF- $\kappa \mathrm{B}$ and AP-1 activity, VEGF mRNA upregulation and the resultant increase in DNA synthesis in microvascular endothelial cells. ${ }^{54}$ The influence of curcumin on the level of AGEs and the cross-linking of collagen in diabetic rats were studied. ${ }^{55} \mathrm{~A}$ correlation between the level of AGEs and collagen cross-linking was noted. It was further found that accelerated accumulation of AGEcollagen in diabetic animals was prevented by curcumin. The preventive effect of curcumin on the advanced glycation and cross-linking of collagen was pronounced. Results from this report demonstrated the role of curcumin administration in the prevention of AGE-induced complications of diabetes mellitus. ${ }^{55}$ Additional in vivo experiments are necessary to verify the in vitro observed protective role of curcumin in attenuating the AGE effects on the activation of HSCs.

In conclusion, results in this report supported our initial hypothesis and demonstrated that AGEs stimulated HSC activation, which was eliminated by curcumin at least partially by inducing the $A G E-R 1$ gene expression. This process was likely mediated by inhibiting ERK activity, inducing gene expression of PPAR $\gamma$ and sequentially stimulating its transactivity. These results were summarized in Figure 10. The authors admit that the evidence presented in this report is somewhat indirect. Experiments with high expression of AGE-R1 in HSCs by stable transfection with exogenous AGER1 cDNA, and knockdown expression of AGE-R1 by RNA interference technology, including small interfering RNA, would provide more direct evidence to the involvement and role of AGE-R1 in mediating the curcumin inhibition of AGE-induced HSC activation. These experiments are

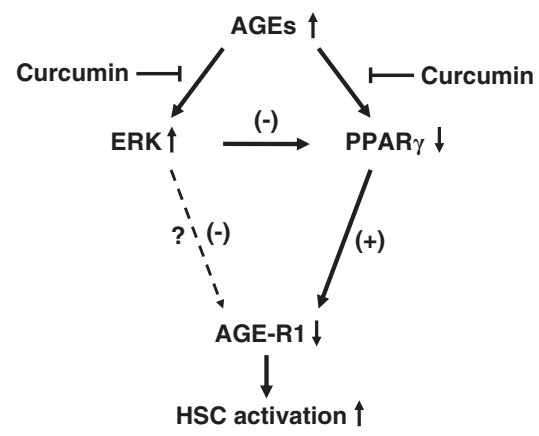

Figure $10 \mathrm{~A}$ simplified action model of advanced glycation end-products (AGEs) and curcumin in regulating the activation of hepatic stellate cells (HSCs). AGEs stimulated HSC activation, which was eliminated by curcumin by inducing expression of AGE receptor-1 (AGE-R1) gene. The process was likely mediated by inhibiting the extracellular signal-regulated kinase (ERK) activity, inducing gene expression of peroxisome proliferator-activated receptor-gamma (PPAR $\gamma$ ) and sequentially stimulating its transactivity. ' $\uparrow$ ' or ' $\downarrow$ ' indicates the effect of AGEs. 
ongoing in our laboratory. It bears emphasis that our results do not exclude any other mechanisms by which curcumin eliminates the stimulatory effects of AGEs on the activation of HSCs and induces gene expression of AGE-R1 in HSCs. It remains unknown how the curcumin-caused inhibition of ERK and stimulation of PPAR $\gamma$ activity could result in the induction of gene expression of AGE-R1 in HSCs. Additional experiments are necessary to explore the underlying molecular mechanisms. The results from this study provide novel insight into effects of diabetes-associated AGEs on inducing HSC activation and hepatic fibrogenesis, the roles and underlying mechanisms of curcumin in abrogating the stimulatory effects of AGEs.

\section{ACKNOWLEDGEMENT}

This work was supported by the Grant DK 47995 from NIH/NIDDK to A Chen.

\section{DISCLOSURE/CONFLICT OF INTEREST}

The authors declare no conflict of interest.

1. Tsochatzis E, Papatheodoridis GV, Manesis EK, et al. Metabolic syndrome is associated with severe fibrosis in chronic viral hepatitis and non-alcoholic steatohepatitis. Aliment Pharmacol Ther 2008;27: 80-89.

2. Clark JM. The epidemiology of nonalcoholic fatty liver disease in adults. J Clin Gastroenterol 2006;40(Suppl 1):S5-10.

3. Bierhaus $A$, Humpert PM, Morcos $M$, et al. Understanding RAGE, the receptor for advanced glycation end products. J Mol Med 2005; 83:876-886.

4. Brownlee M. The pathobiology of diabetic complications: a unifying mechanism. Diabetes 2005;54:1615-1625.

5. Libby P, Plutzky J. Diabetic macrovascular disease: the glucose paradox? Circulation 2002;106:2760-2763.

6. Schmidt AM, Yan SD, Yan SF, et al. The biology of the receptor for advanced glycation end products and its ligands. Biochim Biophys Acta 2000;1498:99-111.

7. Lu C, He JC, Cai W, et al. Advanced glycation endproduct (AGE) receptor 1 is a negative regulator of the inflammatory response to AGE in mesangial cells. Proc Natl Acad Sci USA 2004;101:11767-11772.

8. Brett J, Schmidt AM, Yan SD, et al. Survey of the distribution of a newly characterized receptor for advanced glycation end products in tissues. Am J Pathol 1993;143:1699-1712.

9. Li YM, Mitsuhashi T, Wojciechowicz D, et al. Molecular identity and cellular distribution of advanced glycation endproduct receptors: relationship of p60 to OST-48 and p90 to $80 \mathrm{~K}-\mathrm{H}$ membrane proteins. Proc Natl Acad Sci USA 1996;93:11047-11052.

10. Friedman SL. Mechanisms of hepatic fibrogenesis. Gastroenterology 2008;134:1655-1669.

11. Friedman SL, Rockey DC, McGuire RF, et al. Isolated hepatic lipocytes and Kupffer cells from normal human liver: morphological and functional characteristics in primary culture. Hepatology 1992;15:234-243.

12. Kisseleva T, Brenner DA. Hepatic stellate cells and the reversal of fibrosis. J Gastroenterol Hepatol 2006;21(Suppl 3):S84-S87.

13. Calamita G, Portincasa P. Present and future therapeutic strategies in non-alcoholic fatty liver disease. Expert Opin Ther Targets 2007;11: 1231-1249.

14. O'Connell MA, Rushworth SA. Curcumin: potential for hepatic fibrosis therapy? Br J Pharmacol 2008;153:403-405.

15. Fu Y, Zheng S, Lin J, et al. Curcumin protects the rat liver from CCl4caused injury and fibrogenesis by attenuating oxidative stress and suppressing inflammation. Mol Pharmacol 2008;73:399-409.

16. $\mathrm{Xu} \mathrm{J,} \mathrm{Fu} \mathrm{Y,} \mathrm{Chen} \mathrm{A.} \mathrm{Activation} \mathrm{of} \mathrm{peroxisome} \mathrm{proliferator-activated}$ receptor-gamma contributes to the inhibitory effects of curcumin on rat hepatic stellate cell growth. Am J Physiol Gastrointest Liver Physiol 2003;285:G20-G30.
17. Zheng $\mathrm{S}$, Chen A. Activation of PPARgamma is required for curcumin to induce apoptosis and to inhibit the expression of extracellular matrix genes in hepatic stellate cells in vitro. Biochem J 2004;384(Part 1): 149-157.

18. Zheng S, Yumei $F$, Chen A. De novo synthesis of glutathione is a prerequisite for curcumin to inhibit hepatic stellate cell (HSC) activation. Free Radic Biol Med 2007;43:444-453.

19. Hyogo $\mathrm{H}$, Yamagishi S, Iwamoto $\mathrm{K}$, et al. Elevated levels of serum advanced glycation end products in patients with non-alcoholic steatohepatitis. J Gastroenterol Hepatol 2007;22:1112-1119.

20. Iwamoto K, Kanno K, Hyogo H, et al. Advanced glycation end products enhance the proliferation and activation of hepatic stellate cells. J Gastroenterol 2008;43:298-304.

21. Makita Z, Vlassara $H$, Cerami A, et al. Immunochemical detection of advanced glycosylation end products in vivo. J Biol Chem 1992; 267:5133-5138.

22. Monnier VM, Kohn RR, Cerami A. Accelerated age-related browning of human collagen in diabetes mellitus. Proc Natl Acad Sci USA 1984;81:583-587.

23. Wrobel K, Wrobel K, Garay-Sevilla ME, et al. Novel analytical approach to monitoring advanced glycosylation end products in human serum with on-line spectrophotometric and spectrofluorometric detection in a flow system. Clin Chem 1997;43:1563-1569.

24. Miele C, Riboulet A, Maitan MA, et al. Human glycated albumin affects glucose metabolism in L6 skeletal muscle cells by impairing insulininduced insulin receptor substrate (IRS) signaling through a protein kinase C alpha-mediated mechanism. J Biol Chem 2003;278: 47376-47387.

25. Camp HS, Chaudhry A, Leff T. A novel potent antagonist of peroxisome proliferator-activated receptor gamma blocks adipocyte differentiation but does not revert the phenotype of terminally differentiated adipocytes. Endocrinology 2001;142:3207-3213.

26. Lin J, Zheng S, Chen A. Curcumin attenuates the effects of insulin on stimulating hepatic stellate cell activation by interrupting insulin signaling and attenuating oxidative stress. Lab Invest 2009;89: 1397-1409.

27. Schmittgen TD, Zakrajsek BA, Mills AG, et al. Quantitative reverse transcription-polymerase chain reaction to study mRNA decay: comparison of endpoint and real-time methods. Anal Biochem 2000;285:194-204.

28. Chen A, Beno DW, Davis BH. Suppression of stellate cell type I collagen gene expression involves AP-2 transmodulation of nuclear factor-1dependent gene transcription. J Biol Chem 1996;271:25994-25998.

29. Chen A, Zheng S. Curcumin inhibits connective tissue growth factor gene expression in activated hepatic stellate cells in vitro by blocking NF-kappaB and ERK signalling. Br J Pharmacol 2008;153:557-567.

30. Zheng $\mathrm{S}$, Chen A. Curcumin suppresses the expression of extracellular matrix genes in activated hepatic stellate cells by inhibiting gene expression of connective tissue growth factor. Am J Physiol Gastrointest Liver Physiol 2006;290:G883-G893.

31. Zhou Y, Zheng S, Lin J, et al. The interruption of the PDGF and EGF signaling pathways by curcumin stimulates gene expression of PPARgamma in rat activated hepatic stellate cell in vitro. Lab Invest 2007;87:488-498.

32. Lin J, Chen A. Activation of peroxisome proliferator-activated receptorgamma by curcumin blocks the signaling pathways for PDGF and EGF in hepatic stellate cells. Lab Invest 2008;88:529-540.

33. Tsukamoto $\mathrm{H}$, She $\mathrm{H}$, Hazra $\mathrm{S}$, et al. Anti-adipogenic regulation underlies hepatic stellate cell transdifferentiation. J Gastroenterol Hepatol 2006;21(Suppl 3):S102-S105.

34. Tang $\mathrm{Y}$, Zheng S, Chen A. Curcumin eliminates leptin's effects on hepatic stellate cell activation via interrupting leptin signaling. Endocrinology 2009;150:3011-3020.

35. Kang Q, Chen A. Curcumin suppresses expression of low-density lipoprotein ( $L D L)$ receptor, leading to the inhibition of LDL-induced activation of hepatic stellate cells. Br J Pharmacol 2009;157:1354-1367.

36. Kang $\mathrm{Q}$, Chen $\mathrm{A}$. Curcumin eliminates oxidized LDL roles in activating hepatic stellate cells by suppressing gene expression of lectin-like oxidized LDL receptor-1. Lab Invest 2009;89:1275-1290 .

37. Lin J, Chen A. Curcumin diminishes the impacts of hyperglycemia on the activation of hepatic stellate cells by suppressing membrane translocation and gene expression of glucose transporter-2. Mol Cell Endocrinol 2011;333:160-171. 
38. Sourris KC, Forbes JM. Interactions between advanced glycation endproducts (AGE) and their receptors in the development and progression of diabetic nephropathy - are these receptors valid therapeutic targets. Curr Drug Targets 2009;10:42-50.

39. Tanji N, Markowitz GS, Fu C, et al. Expression of advanced glycation end products and their cellular receptor RAGE in diabetic nephropathy and nondiabetic renal disease. J Am Soc Nephrol 2000;11:1656-1666.

40. Torreggiani $\mathrm{M}$, Liu $\mathrm{H}, \mathrm{Wu}$ J, et al. Advanced glycation end product receptor-1 transgenic mice are resistant to inflammation, oxidative stress, and post-injury intimal hyperplasia. Am J Pathol 2009;175: 1722-1732.

41. Yamagishi S, Nakamura K, Matsui T, et al. Agents that block advanced glycation end product (AGE)-RAGE (receptor for AGEs)-oxidative stress system: a novel therapeutic strategy for diabetic vascular complications. Expert Opin Investig Drugs 2008;17:983-996.

42. Vlassara H, Uribarri J, Cai W, et al. Advanced glycation end product homeostasis: exogenous oxidants and innate defenses. Ann NY Acad Sci 2008;1126:46-52.

43. Cai W, He JC, Zhu L, et al. AGE-receptor-1 counteracts cellular oxidant stress induced by AGEs via negative regulation of p66shc-dependent FKHRL1 phosphorylation. Am J Physiol Cell Physiol 2008;294: C145-C152.

44. Sreejayan, Rao MN. Curcuminoids as potent inhibitors of lipid peroxidation. J Pharm Pharmacol 1994;46:1013-1016.

45. Camp HS, Tafuri SR. Regulation of peroxisome proliferator-activated receptor gamma activity by mitogen-activated protein kinase. J Biol Chem 1997;272:10811-10816.

46. Camp HS, Tafuri SR, Leff T. c-Jun N-terminal kinase phosphorylates peroxisome proliferator-activated receptor-gamma1 and negatively regulates its transcriptional activity. Endocrinology 1999;140:392-397.
47. Sharma RA, McLelland $\mathrm{HR}$, Hill $\mathrm{KA}$, et al. Pharmacodynamic and pharmacokinetic study of oral Curcuma extract in patients with colorectal cancer. Clin Cancer Res 2001;7:1894-1900.

48. Garcea G, Jones DJ, Singh R, et al. Detection of curcumin and its metabolites in hepatic tissue and portal blood of patients following oral administration. Br J Cancer 2004;90:1011-1015.

49. Butscheid M, Schafer C, Brenner S, et al. Unchanged serum levels of advanced glycation endproducts in patients with liver disease. Naunyn Schmiedebergs Arch Pharmacol 2007;375:401-406.

50. Scharnagl $\mathrm{H}$, Stojakovic $\mathrm{T}$, Winkler $\mathrm{K}$, et al. The HMG-CoA reductase inhibitor cerivastatin lowers advanced glycation end products in patients with type 2 diabetes. Exp Clin Endocrinol Diabetes 2007; 115:372-375.

51. Basta G, Sironi AM, Lazzerini G, et al. Circulating soluble receptor for advanced glycation end products is inversely associated with glycemic control and S100A12 protein. J Clin Endocrinol Metab 2006; 91:4628-4634.

52. Schiel R, Franke S, Appel T, et al. Improvement in quality of diabetes control and concentrations of AGE-products in patients with type 1 and insulin-treated type 2 diabetes mellitus studied over a period of 10 years (JEVIN). J Diabetes Complications 2003;17:90-97.

53. Ghanem AA, Elewa A, Arafa LF. Pentosidine and N-carboxymethyllysine: biomarkers for type 2 diabetic retinopathy. Eur J Ophthalmol 2011;21:48-54.

54. Okamoto T, Yamagishi S, Inagaki Y, et al. Angiogenesis induced by advanced glycation end products and its prevention by cerivastatin FASEB J 2002;16:1928-1930.

55. Sajithlal GB, Chithra P, Chandrakasan G. Effect of curcumin on the advanced glycation and cross-linking of collagen in diabetic rats. Biochem Pharmacol 1998;56:1607-1614. 